\title{
Article \\ Effects of an Interdisciplinary Course on Pre-Service Primary Teachers' Content Knowledge and Academic Self-Concepts in Science and Technology-A Quantitative Longitudinal Study
}

\author{
Melanie Marita Beudels ${ }^{1, *}$, Karsten Damerau ${ }^{2}$ and Angelika Preisfeld ${ }^{1}$ \\ 1 Department of Zoology and Biology Education, University of Wuppertal, 42119 Wuppertal, Germany; \\ apreis@uni-wuppertal.de \\ 2 Department of Ecology and Environmental Education, European University of Flensburg, \\ 24943 Flensburg, Germany; Karsten.Damerau@uni-flensburg.de \\ * Correspondence: melanie.beudels@uni-wuppertal.de
}

Citation: Beudels, M.M.; Damerau, K.; Preisfeld, A. Effects of an Interdisciplinary Course on Pre-Service Primary Teachers' Content Knowledge and Academic Self-Concepts in Science and Technology-A Quantitative Longitudinal Study. Educ. Sci. 2021 11,744. https://doi.org/10.3390/ educsci11110744

Academic Editors: Ching-Sing Chai and James Albright

Received: 23 September 2021

Accepted: 10 November 2021

Published: 17 November 2021

Publisher's Note: MDPI stays neutral with regard to jurisdictional claims in published maps and institutional affiliations.

Copyright: (c) 2021 by the authors. Licensee MDPI, Basel, Switzerland. This article is an open access article distributed under the terms and conditions of the Creative Commons Attribution (CC BY) license (https:/ / creativecommons.org/licenses/by/ $4.0 /)$.

\begin{abstract}
Primary school teachers need adequate professional knowledge and motivational orientations to qualify scientifically and technologically literate students. Previous studies have focused on the impact of coursework on (pre-service) primary teachers' content knowledge, rather than on the development of academic self-concepts. In addition, the influence of the course format and the major field of study has not been investigated much to this date. Thus, this study examines the effects of an interdisciplinary course on pre-service primary teachers' content knowledge and academic self-concepts in science and technology using a quasi-experimental, quantitative, pre-post-follow-up design ( $n=202$ ). Whilst no significant changes in knowledge were revealed for the baseline group not participating in the course, significant short-term and long-term cognitive gains were found for the experimental group. Biology-, chemistry-, physics- and technology-related self-concepts increased significantly when participating in the course. The results also indicate that the course format and major field of study can have an impact on the development of pre-service teachers' professional knowledge. Regarding the development of academic self-concepts in the experimental group, it can be assumed that both the weekly and block course format are beneficial for heterogeneous learner groups consisting of pre-service teachers with different major fields of study.
\end{abstract}

Keywords: teacher education; pre-service primary school teachers; content knowledge; academic self-concept; interdisciplinarity; intervention

\section{Introduction}

Worldwide, the aim of science and technology education in primary school is to develop pupils' scientific [1] and technological literacy [2]. Children should acquire competencies enabling them to participate and act responsibly in this science- and technologyoriented, multi-perspective world. Every day, they encounter numerous phenomena such as rainbows, the "disappearance" of water from its puddle or the floating of a giant ship in a river. Primary science and technology lessons are intended to help them better understand these phenomena. However, it is not just about gaining knowledge and procedural skills, being familiar with some of the fundamental concepts and fostering conceptual change to overcome non-scientific concepts. The goal is also to contribute to positive motivational orientations, thus reinforcing self-confidence and interest in science and technology [2-7].

In addition to pedagogical content knowledge (PCK) and pedagogical knowledge $(\mathrm{PK})$, primary school teachers need adequate content knowledge $(\mathrm{CK})$ in the domains of biology, chemistry, physics and technology to plan and deliver instruction that meets the above goals [8-11]. CK is seen as a basis for the development of PCK and influences the actions of teachers (for details, see Section 1.1). If a primary teacher wants children to explore natural phenomena, he/she needs CK in all related disciplines to design the lesson 
so that a conceptual change can take place $[8,12]$. For example, he or she needs CK in biology to explain the behavior of a water strider gliding on the water surface. He/she also needs CK in chemistry and physics to understand the principle of the surface tension of water. Thus, to design instruction appropriate to our multifaceted world, primary teachers also require interdisciplinary CK $[8,13]$.

However, teachers' instructional practices are influenced not only by their actual professional knowledge but also significantly by their motivational orientations [11,14], such as their academic self-concepts (ASCs). ASCs, "describing our self-beliefs about our intellectual strengths and weaknesses" ([15] p. 187), are not the inner mirror of our actual knowledge and skills, but they reflect our self-perceived reality $[15,16]$. If a teacher does not feel competent in a particular domain (e.g., physics), he/she will tend to avoid topics from that area in class, even though his/her CK and PCK might be sufficient to make instruction effective for learning $[17,18]$. Given this relevance to teacher behavior (see Section 1.2 for details), positive biology-, chemistry-, physics- and technology-related ASCs are desirable [17,19-21].

However, there is consistent evidence that science- and technology-related CK [22-28] and ASCs $[17,18,20]$ of pre- and in-service primary teachers tend to be low (for an overview see [29]). They often have the same misconceptions as the children they teach [28,30,31]. Regarding ASCs, chemistry-, physics- and technology-related ASCs are rather low, whereas biology-related ASCs are often higher [32,33]. These findings echo particular characteristics, challenges and consequences of the primary teacher education system:

Primary teacher candidates frequently have different entry characteristics than secondary teacher candidates: Among other things, they have fewer high school backgrounds in science [34], which can explain lower CK in this area. They are also less confident in maximizing "understanding of the subject matter" and deciding "what content to teach" ([34], p. 50). Primary teacher candidates also exhibit higher intrinsic, pedagogically oriented motives for choosing their course of study; subject interest as a reason for the career decision is given less frequently [34-38]. These career decisions are influenced by ASCs. Thus, if a teacher candidate has a high physics-related ASC, he or she is more likely to choose physics as a major for secondary school teaching rather than a course in primary education in which physics content plays little or no role [15,39]. Given these entry-level characteristics and the relevance of science- and technology-related CK and ASCs to the design of instruction that meets the aforementioned goals of primary science and technology education, university training should therefore ensure that CK and ASCs develop positively. At this point, the primary teacher education system is facing challenges:

1. Teacher generalist training and teaching-out-of-field: In many countries, primary teachers are educated as generalists who have to teach multiple subjects $[29,40,41]$. However, training in three to four or more subjects also implies fewer contact hours per subject [42-45]. This is problematic for the goal of increasing CK and ASCs-positively correlating with the corresponding CK domain (see Section 1.2)—, as it has been shown that the number of contact hours with the subject at the university correlates positively with the level of CK [46]. Primary teachers who took a science major during their studies have a higher science CK than primary teachers without this major [22,45]. In some countries, such as China [7] or Germany [47], science and technology are sometimes not covered at all during studies [43-45]. Nevertheless, primary school teachers then have to teach topics from these disciplines in their role as classroom teachers [48].

2. Subject-integrated teaching — broad study content: With the aim of exploring the multi-perspective world (see above), in many countries, including Japan, France, Austria, The Netherlands, Slovenia, China and Germany, science and technology content is taught within an integrated subject in primary school $[7,45,49,50]$. By the term "integrative" we mean that the subject includes not only biology, chemistry, physics and (sometimes) technology, but also disciplines such as history, social sciences, geography $[7,45,49-51]$. Since this subject is called differently in each country [45], the term 
"General Studies" (Sachunterricht) is used as a generalization in the following. This is the term used in Germany [3], where this study was conducted. Thus, at best, primary teachers should have CK and positive ASCs in all of these disciplines (hereafter used synonymously with the term "domain"; $[13,51])$. Given the interdisciplinary nature of this subject, primary teachers should at the same time be able to think across disciplines and appropriately connect the content of different fields [13].

Thus, in addition to the problem that there is already little time available for each subject due to the training as generalists, General Studies teacher training is faced with ensuring adequate professionalization given the wide range of corresponding disciplines [51].

In summary, there is a large discrepancy between the expectations for science and technology teaching at the primary level and the realities of primary teacher education and teachers' professional competencies. The question arises as to how positive development of pre-service primary teachers' science- and technology-related CK and ASCs can be promoted given the above entry-level characteristics on the one hand, and the limited time resources and the broad range of study content on the other [52]. University courses that combine several disciplines of General Studies (e.g., biology, chemistry and technology) are seen as a possible solution to this dilemma [43,51]. Given the scarce time resources available during the study, this could not only foster professional competencies in several domains simultaneously but also raise awareness of the interdisciplinary nature of the discipline. However, since there is little research on this topic (see Section 1.3), this study examines the effects of an interdisciplinary intervention at the university on pre-service primary teachers' $\mathrm{CK}$ and ASCs in science and technology. In the following, we first summarize the state of the research in order to derive the research questions.

\subsection{Teachers' Content Knowledge: Definition, Structure, Relevance, Operationalization and Influencing Factors}

CK-also called subject matter knowledge [53] — is one of the main facets of teachers' professional knowledge and comprises the deep understanding of the subject matter to be taught $[9,10,54-56]$. It includes knowledge about subject-specific facts, terms, concepts, (content) structures and their interrelationships as well as knowledge about relations to other domains and methods to generate new knowledge $[9,10,57,58]$.

There are several ways to categorize CK [9,10,54]. Following the work of Schwab [59], a distinction is often made between substantive and syntactic CK [60,61]. Syntactic knowledge refers to the knowledge of methods for generating and rules for evaluating subjectspecific knowledge [61,62]. Knowledge of syntax means being familiar with the principles by "which truth or falsehood, validity or invalidity, are established" ([9], p. 9). Substantive knowledge, on the other hand, includes the knowledge that is generated by science, i.e., knowledge about facts, basic concepts, relationships and subject structure $[9,61,62]$. Regarding the type of knowledge, further categorizations and conceptualizations can be found [54,63-65], including declarative ("knowing that" [65]), procedural (knowing how to do something $[54,63]$ ) and conditional (knowing when and why to apply a process or action [64,65]) knowledge. Declarative knowledge relevant to this work comprises theoretical and factual knowledge required to understand the relevant domain. It comprises knowledge of terms, definitions and principles [63,64].

CK is considered an essential prerequisite for the development of PCK [66-71], indicated by high to moderate correlations between these two facets of professional knowledge [72,73]. For the disciplines of biology [68], chemistry [74], physics [75] and technology [76], CK has already been shown to affect PCK, but PCK has not been shown to affect CK. Thus, to some extent, fostering CK is sufficient for the development of PCK [72,77]. Along with this, many studies reveal $\mathrm{CK}^{\prime}$ s impact on the quality of planning lessons, teaching and instructions [58,68,78,79]: Due to a lack of CK, children's misconceptions may not be recognized, the instructional potential of certain concepts may not be realized and insufficient activities may be offered to develop these concepts [12,58,80,81]. Teachers with a high $\mathrm{CK}$ also have a broader repertoire and a higher quality of explanations and strategies 
for explaining and presenting learning content $[70,78,82,83]$. In addition, they plan more cognitively demanding [84], coherent [78] and open learning environments [58], such as inquiry-based science lessons [85]. CK in a particular domain is also related to teachers' motivational orientations (see also Section 1.2). A low science CK has been found to be associated with a low teaching self-efficacy and low confidence regarding science [86-88]. There is also preliminary evidence that primary teachers' CK-mediated by instructional quality-positively impact pupils' learning outcomes [89-91].

Given this importance and impact of CK, a main goal of the teacher education standards is to ensure that prospective teachers acquire sound, structured and reflective CK e.g., $[8,92]$. Theoretically and empirically it has not yet been clarified to what extent and depth (primary) teachers need CK to implement good teaching [8]. However, there is a noticeable consensus that adequate planning of lessons requires $\mathrm{CK}$ that goes beyond the school level in which it is taught [93]. For the field of science education at primary schools, Anders et al. [94] demand that the teachers' CK should at least correspond to the level of the lower secondary level. Since there is no consensus on the breadth and depth of teachers' $\mathrm{CK}$, operationalizing knowledge in terms of difficulty levels is handled differently in research studies $[75,95,96]$. In the TEDS-M study, for instance, a distinction was made between novice ("content that is typically taught at the grades the future teacher will teach" [95], p. 436), intermediate (one or two years beyond the grade levels taught) and advanced (three or more years beyond) levels of difficulty [97]. Ohle and colleagues, in developing a physics CK questionnaire for pre- and in-service primary teachers, made sure that there were items with references to primary, secondary and university textbooks $[91,96,98]$. Simultaneously, they differentiated between three levels of complexity: Facts, relations and concepts [91,98].

As mentioned in the introduction, teachers' $\mathrm{CK}$ in a subject correlates positively with the contact time to that subject during the course of study $[22,45,46]$. Overall, many studies suggest that the phase of university studies and attending in-service training are the strongest factors influencing teachers' CK [26,99-101]. Content-focused learning environments, i.e., topic-specific rather than non-topic-specific courses, have been found to be particularly beneficial for CK [102,103]. Moderate constructivist [104,105] settings, where participants can reflect on their concepts, develop them further and exchange ideas with each other, have also proven successful $[17,106]$.

However, teachers' professional competence does not only arise from cognitive variables such as the CK. Affective-motivational characteristics, including self-concept, are also essential to their professional performance [11,107].

\subsection{Teachers' Academic Self-Concept: Definition, Structure, Operationalization, Relevance and Influencing Factors}

Hierarchically structured and multifaceted, self-concept is a person's perception of her- or himself [108]. It arises from the personal set of knowledge, skills and beliefs and is formed through experiences with and influences of the environment [108-110]. The general self-concept can be differentiated into a non-academic and academic self-concept (ASC). The latter includes at least two facets - verbal and mathematic ASC — which can be divided into different subject areas [111,112]. The chemistry- and physics-related ASC are assigned to the math ASC, while the biology-related ASC can be allocated to both the verbal and the math ASC [113,114]. According to Marsh's classification [113], it is to be assumed that the technology-related ASC can at least be subordinated to the mathematical ASC due to its proximity to the subjects of physics and mathematics [115].

Little is known about the structure of teachers' ASC, defined as self-evaluation of their professional knowledge $[116,117]$. The findings of Paulick et al. [116] reveal that teachers' ASC can be subdivided into CK-, PCK- and PK-related components. Regarding science- and technology-related CK ASCs of pre- or in-service primary teachers, previous studies have either focused on one domain — mostly physics $[20,118,119]$ —or their ASC has been examined without checking whether mental discrimination is made between the domains $[32,120]$. However, primary school teachers may not have science domainspecific ASCs at all due to the integrative character of General Studies [3]. Gabriel-Busse 
et al. [121] showed that German primary school children discriminate between science-, technology-, history-, geography- and politics-related ASCs, but not between their selfevaluated abilities in biology, chemistry and physics.

ASC is considered a mediator between experiences of performance in a particular domain and (learning) behavior or motivation related to this domain [122]. A pre-service teacher who has had negative learning experiences with physics in school or the course of study and, as a result, develops a low physics-related ASC [18] is likely to exhibit low learning motivation and engagement in this area in the future $[110,123,124]$. Therefore, it is not surprising that teachers with a positive ASC show different teaching behaviors than teachers with a low ASC [21]. They are more likely to adopt new instructional practices [125], support the development of pupils' motivational orientations, such as their interests [21], and are more tolerant to stress [126]. The ASC also influences whether teachers avoid inquiry-based instructional settings and instead tend to provide expository instruction, which does little to stimulate deep learning $[17,21,29]$. Consequently, in terms of teaching effectiveness, high teacher ASCs can also lead to greater cognitive gains among pupils [127]. Teachers' ASCs also seem to be of relevance in developing other motivational orientations and mediating the interaction of interest and professional knowledge [117].

According to the reciprocal effects model [128], ASC and performance have a reciprocal, mutually reinforcing relationship. Thus, academic achievement impacts and predicts self-concept, and self-concept affects and predicts achievement. Positive correlations of professional knowledge and ASC among pre- and in-service teachers have already been shown for mathematics [129], biology and physics [116,117]. Paulick et al. [116] found positive relationships between CK ASC and CK test scores, PCK ASC and PCK test scores, and PK ASC and PK performance. They conclude that teachers' ASC is a predictor for their performance in the corresponding domain. However, the strength of correlations also suggests that additional factors are influencing their ASCs.

Due to the numerous favorable outcomes of ASCs, many educational interventions in school and colleges aim to develop them positively [32,118,130,131], although altering them is challenging as they are considered rather stable [15]. Little is known about possible factors that affect teachers' ASC during their university education. There is first evidence that external and internal reference norms [112] have an impact on pre-service teachers' ASCs [117,132]. Social comparisons (external reference), take place, for example, when a pre-service teacher compares his performance/skills in a university science course with the performance of fellow students in the same course [16,112,133]. Internal reference norms include temporal (comparison of current performance with past performance), dimensional (comparison of performance in one domain, e.g., biology, with performance in another domain, e.g., chemistry) and criterial (comparison of performance with target criteria, e.g., competence expectations for a teacher) comparisons [16,110,112,134]. In addition to a positive experience of competency, individual oral or written performance feedback and supportive faculty behaviors could also strengthen pre-service teachers' ASCs $[16,110,135,136]$. Furthermore, studies examining the experiment-related ASC $[137,138]$ demonstrate that the major field of study may also be a variable that influences pre-service teachers' ASC.

For the positive development of ASCs with respect to more than one discipline and avoiding fragmented knowledge, interdisciplinary learning environments are considered beneficial $[32,139,140]$. This will be discussed in the next section.

\subsection{Research on the Development of Pre-and In-Service Primary Teachers Science-and Technolgy-Related CK and ASCs through Interdisciplinary Interventions: Status Quo and Research Gaps}

Interdisciplinary courses are seen as one way to address the challenges described in the introduction $[32,43,140]$. By the term "interdisciplinary" we mean that a course deals with topics and questions that require competencies from several disciplines, e.g., biology and technology [141].

Such interdisciplinary learning environments are expected to better connect learning content $[139,140]$. Aström showed for the school context that interdisciplinary learning 
has no disadvantages compared to disciplinary learning in terms of subject knowledge gain [142]. While several studies have revealed positive effects of science content or/and methods courses as well as teacher training on pre- and in-service primary teachers CK $[24,26,101,143]$, there are just a few reports of courses and their effectiveness that focus on more than one discipline of General Studies. Cross-sectional and longitudinal studies often investigate topic- or discipline-specific CK, e.g., CK on "states of matter and phase transitions" [96] or "combustion" [45]. However, this means that the ability to think across disciplines, as explicitly called for in the Minimum Standards for General Studies Teacher Education [13], cannot be tested at all or only to a very limited extent. For a crosssectional study, Niermann [144] developed a questionnaire to examine primary teachers' declarative CK on all five main domains of General Studies. Nevertheless, the questionnaire contains only one question per domain, and no interdisciplinary $\mathrm{CK}$ is required to answer the questions. One of the few longitudinal studies investigating change in pre-service primary teachers' interdisciplinary CK is the study by Kratz and colleagues [102]. Using a concept mapping technique, they demonstrate that interdisciplinary CK (biology and physics) increased significantly as a result of a university seminar linking biology and physics.

For the context of school, studies have shown that interdisciplinary science education leads to a significant increase in science-related ASCs, especially among girls, thereby eliminating the differences between girls and boys [141,145]. Given that the majority of primary school teachers are women [146], a discipline-integrating approach to their university education and training could be useful in positively influencing the often low chemistry-, physics- and technology-related ASCs.

However, there is a global lack of research on the effects of (interdisciplinary) courses on the development of science- and technology-related ASCs of pre- and in-service primary teachers [147]. Those longitudinal studies that do exist tend to focus on only one science domain, with an emphasis on physics-related ASC $[118,119]$, and have yielded mixed results: Technology-related ASC [147] and physics-related ASC [119] of pre-service primary teachers did not change as a result of a single technology-related seminar or two physicsrelated experiment-based seminars, respectively. However, as in studies with pupils who participated in a half-day laboratory course $[130,131]$, experiment-related ASC increased significantly among pre-service primary teachers in [119] as a result of participation in a one-semester course. Kleickmann and colleagues [118] found that five months of physicsrelated in-service primary teacher training with extensive, adaptive scaffolding led to higher physics-related ASCs. In a study involving a very small sample ( $n=19$; [120]), a one-semester course integrating biology and chemistry led to a significant increase in pre-service primary teachers' chemistry-related ASC. Biology-related ASC did not change significantly. Furthermore, Göhring [32] has shown that a program of study including several integrated science modules results in positive development especially of pre-service primary teachers' chemistry- and physics-related ASCs. As university studies progressed, the ASCs stabilized.

\subsection{Research on the Development of Pre-and In-Service Teachers CK and ASCs through Different Course Formats: Status Quo and Research Gaps}

In particular, pre-service primary teachers, who do not study General Studies or do not have a science and technology major, might be interested in block scheduled training, e.g., during the semester break, to enhance their professional competencies in the field of science and technology. Block course formats create curriculum flexibility and are suitable for certain student groups, such as students with parallel time-intensive commitments [148-150]. These "intensive" or "non-traditional" courses do not take place regularly once or twice a week, but in compact time blocks during the semester or lecturefree period. The total number of instructional hours is generally identical to that of "traditional", weekly courses [148,151].

Compared to the context of school, with very mixed results on the impact on academic achievement [152], there are few longitudinal studies on the effectiveness of different 
course formats in higher education, including teacher education [153]. Often, samples are relatively small $[154,155]$ or only subjective impressions about experiences with the course formats are investigated $[153,155,156]$. Most of these studies show that higher education block courses lead to at least equivalent or even greater short- and long-term knowledge gains than weekly courses [154,157-160]. Little research suggests that block teaching leads to poorer performance in higher education institutions [161,162]. One of the main arguments against the pedagogical value of block formats, frequently mentioned in the context of school, is the attention span of learners. During a block course, less learning content may be retained because attention diminishes $[163,164]$. Another counter-argument is that the learning content is better memorized and deepened in weekly courses since there is less input at once, regular processing and repetition $[148,165,166]$.

In contrast to the effects on cognitive gain, there are almost no studies on the impact of the variable "course format" on pre- and in-service teachers' ASC. For the context of school education, Bateson [167] showed that there were significant differences in science achievement between grade- 10 students attending different course formats, but no differences in affective domains. However, he examined science attitudes, not ASCs. [154,159] found that students who participated in a university block course had higher scores on perceived competence than those who participated in the weekly version. This may be an indication that the ASC develops more positively through block courses, as the experience of competency is considered an important factor influencing self-concept [108,135]. According to Burton and Nesbit [151], perception of the ability in a specific domain-in addition to experience with the course format and current subject load-also appears to influence whether students tend to take a block course in the appropriate domain.

\subsection{Aim of the Study}

As described above, primary teachers' CK and ASCs in biology, chemistry, physics and technology play an essential role in supporting pupil learning in General Studies classes $[21,68,90,107]$. However, pre- and in-service primary teachers' CK and ASCs in these disciplines tend to be low $[17,18,20,22-28]$. Previous research (see Section 1.3) suggests that interdisciplinary courses have the potential to positively develop their CK and ASCs regarding several of these disciplines. The few existing research reports on effects of interdisciplinary interventions for pre-service primary teachers in the field of science and technology refer to entire programs of study [32] or examine the impact of a short-time intervention that links only two disciplines [102,120]. For the development of an adequate professional identity and genesis of discipline-interlinking CK $[8,13]$, however, it would be appropriate to integrate all three science disciplines (biology, chemistry, physics) and technology, which is closely interwoven with the natural sciences [168], in a single course. With positive effects on the CK and ASCs, such interdisciplinary course offerings could be a solution for making more effective use of the limited time resources (see introduction) in the primary teacher education program [169].

Thus, this study investigates the impact of an interdisciplinary university course that integrates biology, chemistry, physics and technology (see Section 2.2) on pre-service primary teachers' CK and ASCs in science and technology. The first block of research questions is:

RQ 1: The intervention's impact on CK and ASC in science and technology

RQ 1.1: Does participation in the intervention lead to short-term and long-term gains in CK in science and technology compared to non-participation?

RQ 1.2: Does participation in the intervention lead to a change in biology-, chemistry-, physics- and technology-related ASCs compared to non-participation?

RQ 2: Correlations between cognitive gain and changes in ASCs

Is there a positive correlation between cognitive gain and change in biology-, chemistry-, physics- and technology-related ASCs? 
Referring to the findings of [116] that teachers' ASCs are indicators of their achievements in professional knowledge, the results on RQ 2 are used to assess the external validity of the cognitive test (see Section 2.4.1). Furthermore, studies on the effects of the course format (weekly versus block course format) are mostly situated in the context of schooling $[152,170]$. Few research reports relate to higher education teaching (see Section 1.4; [150]). The influence of this variable is particularly important with respect to further training of pre- and in-service primary teachers who do not have an appropriate university education in science and technology. Due to limited time during the semester or work life, they may be particularly interested in further training in a block format. Thus, the second block of research questions is:

RQ 3: Impact of the course format

RQ 3.1: Are there equivalent short- and long-term cognitive gains between preservice teachers attending a traditional/weekly and an intensive/block course format of the intervention?

RQ 3.2: Does the course format impact the development of biology-, chemistry-, physics- and technology-related ASCs?

Finally, we examine whether both pre-service primary teachers with and without a major field of study in science and technology benefit from the intervention in terms of CK and ASCs. Given the differences in cognitive and affective baselines found in previous studies $[22,45,137]$, it may be possible that one group is under-challenged and the other is over-challenged.

RQ 4: Impact of the major field of study

RQ 4.1: Does the major field of study affect short- and long-term cognitive gains within groups of weekly and block course participants?

RQ 4.2: Does the major field of studies influence the development of biology-, chemistry-, physics- and technology-related ASCs within groups of weekly and block course participants?

\section{Materials and Methods}

\subsection{Research Design}

The cognitive and affective effects of the intervention described in Section 2.2 were investigated using a quasi-experimental pre-post-follow-up design with an experimental group (EG) who attended the intervention and a control group that did not participate in the course (baseline group (BG), see Figure 1). The latter group served to exclude pretest effects and capture effects resulting from participation in other courses or practical experiences. Pretest 1 with the affective questionnaire (see Section 2.4.2) took place directly before the start of the first course unit. The cognitive pretest (pretest 2; see Section 2.4.1) was carried out between the introductory session (unit 1) and the first session with station rotation learning (unit 2, see Figure 1) because the mind mapping in unit 1 should not be influenced by the questions of the knowledge test. The posttest (affective and cognitive test) was administered immediately after the completion of the last unit. Eight weeks after the end of the course the follow-up test (cognitive test) was performed.

There were two EG subgroups that participated in either a weekly or a block course format (see Figure 1, RQ 3 and [137]). To ensure comparability, the BG was also divided into two groups, who completed the questionnaire either at the beginning and end of the lecture period (and eight weeks later for the follow-up test; corresponding to weekly course attendance) or within the time of a block course during the semester break corresponding to block course participation.

Since many variables influence the impact of an intervention, each round of the intervention was always carried out by the same lecturer-accompanied by the same student assistant-in the same room. Therefore, the influence of these variables on the dependent variables is negligible. 


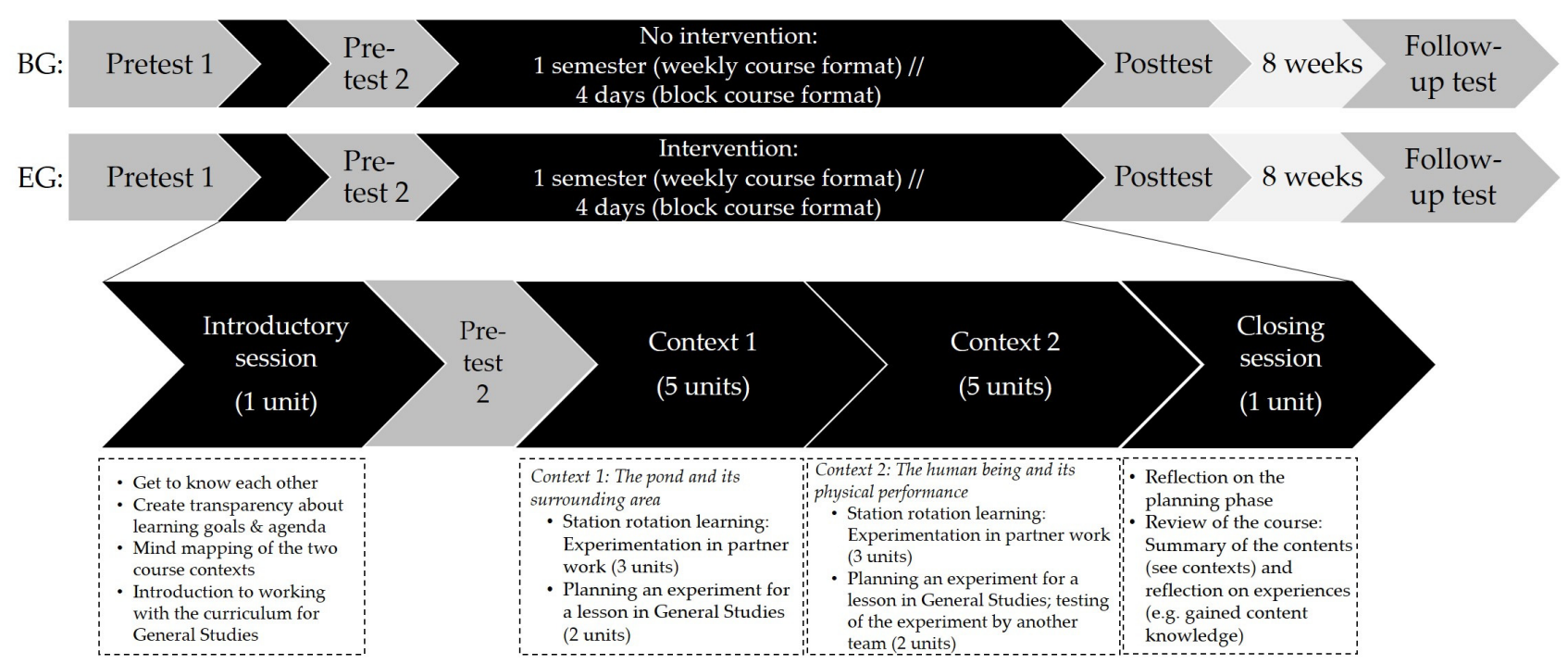

Figure 1. Research design and overview of the units and the intervention's contents (own figure based on [137]).

\subsection{Summary of the Intervention's Educational Concept and the Curricular Framework}

A detailed description of the intervention with implementation instructions can be found in [171]. Therefore, the curricular framework, the target audience and elements of the course particularly relevant to this study are only briefly described here. For the reasons outlined in the introduction, one of the main goals of the intervention is to increase CK and ASCs not only with respect to one subject area of General Studies (e.g., biology), but to strengthen them in several subject areas. In this case, they are biology, chemistry, physics and technology.

The target audience includes pre-service primary teachers currently pursuing bachelor's and master's degrees-regardless of their major field of studies. The reason for admitting students from all kinds of disciplines is that most of them have to teach General Studies without having an appropriate college education [48]. Many participants (e.g., all master's students, bachelor's students specializing in English or social sciences) can only take the course voluntarily due to the existing examination regulations. The only group of students required to participate was bachelor primary teacher candidates majoring in science and technology (SciTec). This was done as part of a pilot project in which the intervention was applied as a substitute for a mandatory module component.

The entire intervention consists of twelve units (see Figure 1), each scheduled for $100 \mathrm{~min}$. As mentioned before, students can either take a traditional, weekly format or attend a four-day block course with three units per day. There is a maximum of 30 participants per intervention to ensure intensive support.

The course is divided into two thematic blocks of five units each, framed by an introductory and a concluding unit (Figure 1). In thematic block 1, the context "the pond and its surrounding" is explored. In block 2, the context is "the human being and its physical performance". These contexts were chosen for the following reasons: 1 . There are many connections to the children's experiences [3,172]. 2. Interdisciplinary interdependencies between the fields of biology, chemistry, physics and technology can be experienced. 3. Following the concept of exemplary in teaching [173], key concepts in science such as matter and energy [168] can be understood. 4 . There are many points of reference to the guidelines of the curriculum for General Studies in North Rhine-Westphalia [174] and the recommendations of the Perspectives Framework for General Studies [3].

Based on the findings of previous studies [106,118], the learning environment was designed according to moderate constructivist learning theory [104,105]. Emphasis is placed on student-centered learning, which is supported by the lecturer. In three units per thematic block, participants acquire scientific and technical CK through a combination 
of station rotation learning and conducting experiments in partner work (see Figure 1). Learning at stations is preceded and followed by activities that are also relevant to this study:

1. Before conducting the experiments: In the introductory session, the participants create a mind map for each of the two contexts noting existing CK on the subjects biology, chemistry, physics and technology. The creation and subsequent review of all mind maps prepared in partner work not only serve to activate prior knowledge but also help to recognize first contextual relationships and get an overview of the course topics [175]. Based on the mind maps' contents, the lecturer finally resolves which of the mentioned contents will be covered in the course.

2. When conducting the experiments: Questions such as "What makes water lilies float on the surface of the water?" and "Why does a small stone sink?" form the starting point of the experimentation process. Considering that most pre-service primary teachers are more interested in biology than the other three subjects [176,177], many of the questions were formulated from a biological perspective to reduce the reservations many primary teachers have about the subjects of chemistry, physics and technology (see Section 1). The station worksheets are designed to develop biological, chemical, physical and technical CK through experimentation. First, hypotheses can be made about the outcome of the experiments. By conducting and interpreting experiments and accompanied by sharing ideas with the team partner, these hypotheses are verified or falsified. Thus, conceptual change [178] is enabled. During this work process, the participants should become aware that there is no division into individual subjects in nature, that many biological or technical phenomena can only be explained by chemical and physical laws and that chemistry [120], physics and technology have high relevance for everyday life $[179,180]$.

3. After conducting the experiments:

a. Background information: For each station a one-page text with further information on the scientific background of the experiment is available. This can be read as a refresher or reinforcement of CK if there is time after the station is completed and before the plenary debrief (see 3b). After each session, digital versions are available in the digital learning room, also containing bibliographical references to simplify further engagement into the topics.

b. Debrief: After each experimental work phase and in the final session, CK gained and interdisciplinary connections experienced are brought together and discussed in the plenary. This debrief is guided by the lecturer, supported by presentation slides with pictures from the experimentation phase and by giving impulses [175].

c. Applying CK: In two additional units per topic block (see Figure 1), participants practice planning experiment-based science/technology lessons by applying and combining CK and PCK to create a child-oriented experiment. In doing so, they can realize that CK is important for the development of PCK [69-71]. As part of this planning, CK that the teacher will need for this experiment is recorded in bullet points on a poster. The lecturer then provides written feedback to the groups on their planning via the digital learning space. Participants have access to feedback for all groups but do not know which people are behind which planning product to avoid social comparisons [112].

\subsection{Sample}

The study was conducted at a university in the federal state of North Rhine-Westphalia (Germany) from winter semester 2017/2018 up to and including summer semester 2019. During this period, the intervention took place eight times: Four times in a weekly and four times in a block course format. The sample included 238 primary teacher students, of whom 191 belonged to the experimental group (EG) while 47 formed the baseline group (BG). Only the records of students who completed the questionnaire at all three measurement 
time points were subjected to data analysis (Section 2.5), resulting in a sample size of $\mathrm{N}_{\text {total }}=202\left(\mathrm{~N}_{\mathrm{EG}}=158 ; \mathrm{N}_{\mathrm{BG}}=44\right)$ with a mean age of 22.65 years $(\mathrm{SD}=2.93$ years $) .79 .2 \%$ of the students were in a bachelor's degree program, $20.8 \%$ were in a master's degree program. $90.1 \%$ of the participants were female. This gender distribution corresponds to the typical situation regarding the teaching staff at German primary schools $(89.4 \%$ female teachers in the school year 2019/2020 [146]). 55.7\% of the EG students attended the weekly, $44.3 \%$ the block course format $\left(\mathrm{N}_{\mathrm{EG}}\right.$, weekly $=88 ; \mathrm{N}_{\mathrm{EG}}$, block $\left.=70\right) .47 .7 \%\left(\mathrm{~N}_{\mathrm{BG}}\right.$, weekly $\left.=21\right)$ of the BG-students completed the questionnaire at the beginning and end of the lecture period and eight weeks later, which corresponds to participation in the weekly course. The other $52.3 \%\left(\mathrm{~N}_{\mathrm{BG}}\right.$, block $\left.=23\right)$ filled in the tests during the time span of a block course, which corresponds to block course attendance. $66.5 \%$ of the participants in the EG studied primary school education with a focus on science and technology (SciTec), the other 33.5\% reported studying primary school teaching with other majors, e.g., English, social or religious studies. Therefore, when selecting participants for the BG, care was taken to ensure a similar distribution of the representatives in terms of the major field of study $\left(\mathrm{N}_{\mathrm{BG}}\right.$, SciTec $=27$; i.e., $61.4 \% ; \mathrm{N}_{\mathrm{BG}}$, no SciTec $=17$; i.e., 38.6\%). For data analysis and interpretation of results, it should be noted that $45.6 \%$ of the EG attended the course voluntarily $\left(\mathrm{N}_{\mathrm{EG}}\right.$, voluntary $\left.=72\right)$, while $54.4 \%\left(\mathrm{~N}_{\mathrm{EG}}\right.$, mandatory $\left.=86\right)$ participated as part of a mandatory module of their studies (see Section 2.2). Due to the examination regulations for elementary school teaching at the university, students without the major SciTec could only participate in the course voluntarily.

\subsection{Instruments and Data Collection}

Data were collected using the SoSci Survey online questionnaire tool [181]. Via the message forum of a digital learning space, information and links to the questionnaires, which included the cognitive and affective test separately, were provided for each reference time point. The test was administered as a power test [182] without time pressure since the intention was to investigate whether the students can answer the questions of the cognitive test correctly in a reasonable time frame. In addition, they were given the opportunity to reflect on their motivational orientations in detail and without pressure. However, participants were asked to complete the questionnaires without interruption and to answer the cognitive test without assistance.

\subsubsection{Cognitive Test}

The cognitive questionnaire assesses substantive, declarative $\mathrm{CK}$ in science and technology covering the intervention's topics (see Section 2.2 and [171], e.g., properties of water, human senses, bionics). Standards of the curriculum for General Studies in North Rhine-Westphalia [174] and recommendations of the Perspectives Framework for General Studies [3] were taken into account to ensure curricular validity. As with Ohle and colleagues [91], the curricular validity of the CK test was also guaranteed by analyzing textbooks from German primary schools, then from secondary schools and subsequently university-level textbooks and handouts for General Studies teachers. Table A1 (Appendix A) lists textbooks and handouts used for some of the topics covered in the test.

Due to the self-construction of the items, they were tested in a preliminary study with pre-service primary teachers and then revised. The final measurement instrument consists of 127 items in the form of 24 multiple-choice questions (each with three to eight items; multiple answer questions), three matching questions (each with three to four items) and three open-ended questions (eight items in total). Since closed-ended questions can be scored rapidly and facilitate the assessment of a large sample [183], they predominate in this questionnaire. According to Bridgeman and Lewis [184], closed-ended items do not necessarily have a lower validity than open-ended items. The order of the questions varied at each reference time to counteract order effects [185].

Based on the consensus that teachers' CK should extend beyond the school level in which it is taught [93] and Anders and colleagues' suggestion that primary school teachers' 
science CK should correspond at least to lower secondary level [94], all items represent secondary school level content. According to the classification by Ohle et al. [91,98] and textbook analysis (see Table A2), most items can also be assigned to primary school content level (26 items) and/or university content level (112 items). Following Ohle and colleagues $[91,98]$ two levels of item complexity were used. Complexity level 1 includes facts (37 items), i.e., single facts and terms. Complexity level 2 covers relations and concepts (90 items), i.e., relating facts to each other, integrating concepts or applying (physical) laws.

To meet the interdisciplinary goals of the course, many questions relate to more than one discipline of General Studies, e.g., biology and chemistry or physics and technology. Sample questions can be found in Table A2. Multiple-choice items and matching items were scored with one point for a correct and zero points for an incorrect answer. Open-ended items were scored with zero to two points using a scoring horizon to ensure objective evaluation.

The criterion validity of the cognitive test was examined by correlating the pre-, posttest and follow-up test scores with the external criterion of students' last biology, chemistry and physics grades at secondary school, since the cognitive test includes topics that are also part of the curriculum in biology, chemistry and physics at this school level. Grades in technology were not correlated with the test results because this subject is not offered in many secondary schools. A correlation with the average grades in biology, chemistry, physics and technology during the study period was not performed as it turned out that many participants had not yet completed a science or technology course. Due to the interdisciplinary nature of the questions, no subdivision of the questions into purely biological, chemical, physical and technical questions was made for the calculation of the correlations (see also Section 4). Criterion validity is confirmed by weak but significant correlations for the domain of biology at all three times of measurement (pre: $r_{\text {biology }}=-0.225$, $p \leq 0.001$; post: $r_{\text {biology }}=-0.156, p=0.026$; follow-up: $\left.r_{\text {biology }}=-0.211, p=0.003\right)$, for the field of chemistry partially (pre: $r_{\text {chemistry }}=-0.125, p=0.076$; post: $r_{\text {chemistry }}=-0.215$, $p=0.002$; follow-up: $r_{\text {chemistry }}=-0.130, p=0.065$ ) and also partially for physics (pre: $r_{\text {physics }}=-0.092, p=0.192$; post: $r_{\text {physics }}=-0.154, p=0.028$; follow-up: $r_{\text {physics }}=-0.169$, $p=0.016)$. The $r$-values are negative since the German grading scale uses 1 for the best and 6 for the worst grade. Furthermore, the external validity of the test is discussed by interpreting the results for RQ 2 (Sections 3.2 and 4).

\subsubsection{Affective Questionnaire}

According to the classification of [116], this study examines CK-related ASCs. ASCs in science (biology, chemistry, physics) and technology were assessed using five-point Likert-type scales ( 1 = I strongly disagree to $5=$ I strongly agree) and three items for each subscale (see Table 1; analogous wording for each subject).

An exploratory factor analysis (EFA; [186]) was carried out to test construct validity as the subscales and items listed in Table 1 were adapted from studies focusing on a different study group in combination with only one reference subject ([187]: Subject: General Studies with focus on physics, study group: In-service primary teachers; [131]: Subject: Biology, study group: High school students). Kaiser-Meyer-Olkin (KMO) measure of sampling adequacy [188] indicated that the sampling was adequate for factor analysis as KMO values were $>0.50$ (pretest: 0.773 ; posttest: 0.790 ; [189]) and Bartlett's test of sphericity [190] was significant ( $p \leq 0.001$; [186]). A principal axis factor analysis with varimax rotation was performed for each time of measurement, including the twelve items shown in Table 1. Considering the theoretical assumptions [186] and the proportions of the total variances [189], a four-factor solution was chosen (see Table A3), which accounted for $75.04 \%$ (pretest) and $76.89 \%$ (posttest) of the variance, respectively. Items with the highest loadings on one common factor were combined into a subscale. Factor loadings of $\lambda \leq 0.50$ were not accepted [191]. No item had to be removed as there were no crossloadings $\lambda \geq 0.40$ [192] or highest loads on an unexpected factor. Factor loadings $\lambda<0.30$, interpreted as low [193], are not shown in Table A3. Moreover, item communalities were 
calculated as they indicate the stability of the factor solutions. The average communalities $h^{2}$ of 0.75 (pretest) and 0.77 (posttest) are greater than 0.50 which is acceptable for sample sizes of approximately 200 persons [194].

Table 1. Affective variables (ASCs) with subscale name, number of items, the wording of the items in German (original) and English, item abbreviations, discriminatory power $r_{i t}$ and reliability (Cronbach's $\alpha$ ).

\begin{tabular}{|c|c|c|c|c|c|c|}
\hline Subscales & $\begin{array}{l}\text { Number of } \\
\text { Items }\end{array}$ & Original Item & Item Translation & $\begin{array}{c}\text { Item } \\
\text { Abbreviation } \\
\text { (Pre/Post) }\end{array}$ & $r_{i t}$ (Pre/Post) & $\begin{array}{l}\text { Cronbach's } \alpha \\
\text { (Pre/Post) }\end{array}$ \\
\hline \multirow{3}{*}{$\begin{array}{l}\text { biology- } \\
\text { related } \\
\text { ASC }\end{array}$} & \multirow{3}{*}{3} & $\begin{array}{l}\text { Biologie liegt mir } \\
\text { nicht besonders *. }\end{array}$ & $\begin{array}{c}\text { Biology doesn't } \\
\text { come easily to me }\end{array}$ & TU31_03/NT19_11 & $0.650 / 0.724$ & \multirow{3}{*}{$0.845 / 0.862$} \\
\hline & & $\begin{array}{l}\text { Ich bin gut in } \\
\text { Biologie. }\end{array}$ & $\begin{array}{c}\text { I am good at } \\
\text { biology. }\end{array}$ & TU31_05/NT19_01 & $0.768 / 0.787$ & \\
\hline & & $\begin{array}{l}\text { Mir fällt es leicht, } \\
\text { neue Inhalte im } \\
\text { Fach Biologie zu } \\
\text { verstehen. }\end{array}$ & $\begin{array}{l}\text { I find it easy to } \\
\text { understand new } \\
\text { content in biology. }\end{array}$ & TU31_08/NT19_06 & $0.732 / 0.708$ & \\
\hline \multirow{3}{*}{$\begin{array}{l}\text { chemistry- } \\
\text { related } \\
\text { ASC }\end{array}$} & \multirow[b]{3}{*}{3} & $\begin{array}{l}\text { Chemie liegt mir } \\
\text { nicht besonders *. }\end{array}$ & $\begin{array}{l}\text { Chemistry doesn't } \\
\text { come easily to me *. }\end{array}$ & TU31_06/NT19_05 & $0.853 / 0.850$ & \multirow{3}{*}{$0.934 / 0.919$} \\
\hline & & $\begin{array}{l}\text { Ich bin gut in } \\
\text { Chemie. }\end{array}$ & $\begin{array}{l}\text { I am good at } \\
\text { chemistry. }\end{array}$ & TU31_11/NT19_10 & $0.879 / 0.871$ & \\
\hline & & $\begin{array}{l}\text { Mir fällt es leicht, } \\
\text { neue Inhalte im } \\
\text { Fach Chemie zu } \\
\text { verstehen. }\end{array}$ & $\begin{array}{l}\text { I find it easy to } \\
\text { understand new } \\
\text { content in } \\
\text { chemistry. }\end{array}$ & TU31_13/NT19_12 & $0.863 / 0.805$ & \\
\hline \multirow{3}{*}{$\begin{array}{l}\text { physics- } \\
\text { related } \\
\text { ASC }\end{array}$} & \multirow{3}{*}{3} & $\begin{array}{l}\text { Ich bin gut in } \\
\text { Physik. }\end{array}$ & $\begin{array}{c}\text { I am good at } \\
\text { physics. }\end{array}$ & TU31_09/NT19_18 & $0.846 / 0.898$ & \multirow{3}{*}{$0.924 / 0.928$} \\
\hline & & $\begin{array}{l}\text { neue Inhalte im } \\
\text { Fach Physik zu } \\
\text { verstehen. }\end{array}$ & $\begin{array}{l}\text { I find it easy to } \\
\text { understand new } \\
\text { content in physics. }\end{array}$ & TU31_14/NT19_15 & $0.844 / 0.840$ & \\
\hline & & $\begin{array}{l}\text { Physik liegt mir } \\
\text { nicht besonders *. }\end{array}$ & $\begin{array}{c}\text { Physics doesn't } \\
\text { come easily to me *. }\end{array}$ & TU31_16/NT19_08 & $0.857 / 0.833$ & \\
\hline \multirow{4}{*}{$\begin{array}{l}\text { technology- } \\
\text { related } \\
\text { ASC }\end{array}$} & \multirow{4}{*}{3} & $\begin{array}{l}\text { Ich bin gut in } \\
\text { Technik. }\end{array}$ & $\begin{array}{l}\text { I am good at } \\
\text { technology. }\end{array}$ & TU31_02/NT19_04 & $0.761 / 0.840$ & \multirow{4}{*}{$0.863 / 0.890$} \\
\hline & & $\begin{array}{l}\text { Technik liegt mir } \\
\text { nicht besonders *. }\end{array}$ & $\begin{array}{l}\text { Technology doesn't } \\
\text { come easily to me *. }\end{array}$ & TU31_15/NT19_14 & $0.720 / 0.779$ & \\
\hline & & Mir fällt es leicht, & I find it easy to & & & \\
\hline & & $\begin{array}{l}\text { neue Inhalte im } \\
\text { Fach Technik zu } \\
\text { verstehen. }\end{array}$ & $\begin{array}{l}\text { understand new } \\
\text { content in } \\
\text { technology. }\end{array}$ & TU31_17/NT19_17 & $0.745 / 0.750$ & \\
\hline
\end{tabular}

* = inversely formulated items that were recoded for analysis.

\subsection{Data Analysis}

Data analyses were carried out using the software SPSS statistics, version 27 (IBM Germany, Ehningen, Germany). Missing values in the data did not be replaced as the survey tool's function for reminding people to answer each item was set.

The cognitive test's open answers were evaluated using a scoring horizon to ensure objectivity. For correct scoring, incorrectly ticked items in the multiple-choice questions were recoded. Posttest items with a difficulty index of $<20 \%$ (overly easy items) and $>80 \%$ (overly difficult items) were eliminated [195] as the cognitive test aims to measure a person's cognitive performance. Ninety-eight items remained for further evaluation. Because the cognitive test examined broad scientific and technical CK, the next step was to exclude all items with discriminability values $r_{i t}<0.1[130,195]$, resulting in 74 items with an internal consistency of Cronbach's $\alpha=0.873$ in the posttest (pretest: $\alpha=0.721$, follow-up test: $\alpha=0.835$ ). Based on George and Mallery's guidelines [196], these values of 
Cronbach's $\alpha$ are considered acceptable and good, respectively. With these 74 remaining items, a maximum of 81 points could be achieved at each reference time.

Since the ASCs examined here were operationalized by tight constructs, item discriminability values $r_{i t}$ should be as high as possible [195]. For this reason, items with discriminability values $r_{i t}<0.3$ with at least one of the two test times were excluded before further analyses were performed (values between $0.3-0.5$ are considered medium, values above 0.5 as high [195]). As can be seen in Table $1, r_{i t}$ values for all items were well above 0.5 at both test times, so no item had to be removed. With Cronbach's $\alpha \geq 0.8$ and $\alpha \geq 0.9$ in the pre- and posttest, the reliabilities of the subscales can be regarded as good and excellent, respectively [196]. To allow comparison, total scores of the affective subscales were normed to a maximum of 5 .

While most statistical tests are relatively robust to slight deviations from a Gaussian distribution [189], the total (normed) scores of all constructs were examined for normal distribution at all test times. Optical methods were also used as Kolmogorov-Smirnov and Shapiro-Wilk tests react very sensitively to minimal deviations from a normal distribution when in larger samples [189]. According to Q-Q plots, values of the skew index $(-3.0 \leq \mathrm{SI} \leq 3.0)$ and Fisher kurtosis (<8.0; [197]), data were normally distributed. Thus, parametric tests could be applied for cross-sectional and longitudinal comparisons. To exclude ceiling and floor effects [195], the pre-test means of all scales were examined for extremely high and extremely low values.

For longitudinal comparisons over two or three measurement times and between two groups, the following procedure-adapted from Damerau [131]—was chosen: Initially, independent samples $t$-tests [189] served to explore pretest differences between the two groups.

In case of no a priori differences, two-way repeated measures analyses of variance (ANOVAs) were performed to answer RQ 1 and 3, with the first factor being time (withinsubject) and the second factor being the main comparison group (between-subject). When interpreting the results, the interaction effect, i.e., the interaction between the factors, is decisive [198]. This interaction effect provides information on whether there is a significant difference in the development of the dependent variables between the two groups over time.

The influence of the variables "type of participation" (voluntary/mandatory) respectively "major field of studies" (SciTec/non-SciTec) was factored out by conducting three-way repeated measures ANOVAs with an additional between-subject factor representing the factored-out variable to be able to attribute possible changes in the dependent variables to the impact of the course format (RQ 3). Since the two factored-out factors are nominally scaled, they were included as between-subject factors rather than as covariates for which a metric scale level is required [191]. It was not possible to include both betweensubject factors simultaneously. The reason for this is the existing examination regulations, by which non-SciTecs can only participate voluntarily, resulting in a subgroup sample size of $n_{\text {non-SciTec+mandatory participation }}=0$.

In case of significant pretest differences between two groups, analyses of covariance (ANCOVAs; [191]) were applied with the pretest scores as the covariate, posttest or followup test scores as the dependent variable and one (RQ 1: Treatment; RQ 4: Major) or two (RQ 3; course format + the respective factored-out variable) independent variables as fixed factors. This setting partializes out the influence of the covariate and the second fixed factor (RQ 3) on the dependent variable. When interpreting the results, the main effect of the first fixed factor in each case (RQ 1: Treatment; RQ 3: Course format; RQ 4: Major) on the dependent variables is crucial. Interaction effects of fixed factor 1 and fixed factor 2 are also reported. These effects indicate that the interaction of both factors affects the knowledge gain or the development of the ASCs, respectively.

The following procedure was used to localize the previously identified differences: In the case of three measurement times (CK) one-way repeated measures ANOVAs were first conducted for each group to investigate whether knowledge changed significantly over 
time. If a significant change in knowledge was found, paired samples $t$-tests [189] were conducted to determine time spans in which significant changes occurred (pre-/posttest; pre-/follow-up test and post-/follow-up test). In the case of two measurement times (ASCs) paired samples $t$-tests were performed to examine pre-post differences within a group.

To answer RQ 3, the impact of the variables "type of participation" or "major field of studies" on the dependent variables again had to be factored out. Thus, instead of one-way repeated measures ANOVAs and paired samples $t$-tests, two-factor (pairwise) repeated measures ANOVAs [198] were employed. The variable "time" was used as within-subject factor and the factored-out variable ("type of participation" or "major field of studies") as between-subject factor. The main effect was considered to determine the impact of the factor "time" on the dependent variable [198].

Prior to performing the independent samples t-tests and ANCOVAs, Levene's tests were applied to assess the homogeneity of variances of the two populations. In case of unequal variances, Welch-tests were subsequently used [189]. Besides, before conducting repeated measures ANOVAs with three times of measurement, Mauchly's test of sphericity was used to test for equality of variances of differences. If the Mauchly's test was significant, correction procedures were applied (Greenhouse-Geisser epsilon $\varepsilon>0.75$ : Huynh-Feldt correction; $\varepsilon<0.75$ : Greenhouse-Geisser correction [199]).

For paired samples $t$-tests and $\mathrm{AN}(\mathrm{C}) \mathrm{OVAs}$, partial eta-squared $\left(\eta_{\mathrm{p}}{ }^{2}\right)$ is reported as effect size [198,200], with $0.01 \leq \eta_{\mathrm{p}}{ }^{2}<0.06$ representing a small effect, $0.06 \leq \eta_{\mathrm{p}}{ }^{2}<0.14$ a medium effect and $\eta_{\mathrm{p}}{ }^{2} \geq 0.14$ representing a large effect [201]. For independent samples $t$-tests, the effect size omega squared $\left(\omega^{2}\right)$ is reported. Values of $0.01 \leq \omega^{2}<0.06$ are interpreted as a small effect, $0.06 \leq \omega^{2}<0.15$ as a medium effect and $\omega^{2} \geq 0.15$ as a large effect [202].

To answer RQ 2, cognitive gain and changes in ASCs were first calculated by determining the differences between pre- and posttest for each participant. Then, Pearson $r$ correlations were used to investigate the strength of the relationship [189] between cognitive gain and change in ASCs (Pearson correlation coefficient of $|r| \geq 0.1$ : Weak/small correlation; $|r| \geq 0.3$ : Moderate correlation; $|r| \geq 0.5$ : Strong/large correlation [201]).

\section{Results}

3.1. Impact of the Intervention: Comparison of $E G$ and $B G$

3.1.1. Content Knowledge (RQ 1.1)

For the EG and BG, average cognitive test scores were examined for all three reference times. Table 2 shows corresponding means, standard deviations, $p$-values and effect sizes $\eta_{\mathrm{p}}^{2}$ for inner- and intergroup comparisons.

Table 2. Means (M) and standard deviations (SD) of declarative CK at all three measurement times comparing EG ( $n=158)$ and BG $(n=44)$. $p$-values and effect sizes $\eta_{\mathrm{p}}{ }^{2}$ are given for inner- and intergroup comparison.

\begin{tabular}{|c|c|c|c|c|c|c|c|}
\hline Group & Reference Time & $\mathbf{M}$ & SD & $p$ & $\eta_{p}^{2}$ & $p_{\text {groups }}$ & $\eta_{p, \text { groups }}{ }^{2}$ \\
\hline \multirow{4}{*}{ EG } & Pre & 36.61 & 8.61 & & & \multirow{6}{*}{$0.000^{* * * *}$} & \multirow{6}{*}{0.285} \\
\hline & Post & 53.18 & 9.99 & $0.000^{* * *}$ & 0.686 & & \\
\hline & Follow-up & 51.66 & 9.28 & & & & \\
\hline & Pre & 36.45 & 6.70 & & & & \\
\hline \multirow{2}{*}{ BG } & Post & 36.23 & 9.43 & 0.142 & 0.044 & & \\
\hline & Follow-up & 37.93 & 7.74 & & & & \\
\hline
\end{tabular}

Significance level: $p \leq 0.001$ highly significant ${ }^{* * *}$ [203]; effect size: $0.01 \leq \eta_{\mathrm{p}}{ }^{2}<0.06$ : Small effect, $0.06 \leq \eta_{\mathrm{p}}{ }^{2}<0.14$ : Medium effect, $\eta_{\mathrm{p}}{ }^{2} \geq 0.14$ : Large effect [201].

According to the result of independent samples $t$-test, there is no significant difference in test scores between EG and BG at the time of pretest $\left(t(200)=0.114, p=0.910, \omega^{2} \leq 0.001\right)$. This means both groups had very similar declarative $C K$ regarding the course contents prior to the intervention. At this point, both groups scored on average less than half of the 
maximum score of 81 points $\left(\mathrm{M}_{\mathrm{EG}}=36.61 ; \mathrm{M}_{\mathrm{BG}}=36.45\right)$. Floor and ceiling effects [195] can therefore be excluded.

Due to the similarity of pretest means, a two-way repeated measures ANOVA was conducted to detect a significant group/treatment ${ }^{*}$ reference time interaction. With Mauchly's test of sphericity being significant (Mauchly- $W(2)=0.848, p \leq 0.001$ ) and GreenhouseGeisser epsilon $\varepsilon>0.75$, a Huynh-Feldt correction was applied for calculation. The ANOVA shows that the EG is significantly different from BG in terms of cognitive gain across the three measurement time points $\left(F(1.760,351.902)=79.644, p \leq 0.001, \eta_{p}{ }^{2}=0.285\right)$; the effect size is large.

The following steps served to locate the observed differences: First, one-way repeated measures ANOVAs were conducted to investigate whether CK within EG and BG changed significantly over time. Since in the EG Mauchly's test of sphericity was significant (Mauchly-W(2) $=0.816, p \leq 0.001$ ) and Greenhouse-Geisser epsilon was $\varepsilon>0.75$, the Huynh-Feldt correction was used: CK increased significantly over the three measurement times $\left(F(1.706,267.782)=343.798, p \leq 0.001, \eta_{\mathrm{p}}{ }^{2}=0.686\right)$. The large effect size indicates a statistically significant difference. On the other hand, there was no significant change in CK over time in the BG $\left(F(2,86)=1.997, p=0.142, \eta_{\mathrm{p}}{ }^{2}=0.044\right)$. Pretest effects or effects resulting from participation in other courses or practical experiences can thus be excluded.

Paired samples $t$-tests were then performed to localize the identified differences in the EG's test scores: CK increased significantly from pre- to posttest $(t=-20.706, p \leq 0.001$, $\left.\eta_{\mathrm{p}}{ }^{2}=0.740, n=158\right)$ and from pre- to follow-up test $\left(t=-20.545, p \leq 0.001, \eta_{\mathrm{p}}{ }^{2}=0.729\right.$, $n=158$ ) with large effect sizes. However, it should also be noted that knowledge decreases significantly between post- and follow-up test, but the effect size is small $(t=2.834, p=0.005$, $\left.\eta_{\mathrm{p}}^{2}=0.049, n=158\right)$.

Overall, the results reveal both significant short-term and long-term gains of declarative CK for the participants of the intervention.

\subsubsection{Academic Self-Concepts (RQ 1.2)}

As shown in Table 3, the biology-related ASC is highest in both the EG $(\mathrm{M}=3.74)$ and $\mathrm{BG}(\mathrm{M}=3.93)$ before the start of the intervention, followed by the technology-related ASC $\left(\mathrm{M}_{\mathrm{EG}}=3.20 ; \mathrm{M}_{\mathrm{BG}}=3.19\right)$. The chemistry- and physics-related ASC s are rated the lowest $(2.71 \leq \mathrm{M} \leq 3.06)$. Especially for the last three subscales, floor- and ceiling effects [195] can be neglected as extremely high or extremely low mean values are not present.

Independent samples $t$-tests revealed no significant differences between the two groups in the pretest for all four ASC constructs (biology: $t(200)=-1.294, p=0.197$, $\omega^{2}=0.003$; chemistry: $t(200)=1.673, p=0.096, \omega^{2}=0.009$; physics: $t(200)=1.808, p=0.072$, $\omega^{2}=0.011$; technology: $\left.t(200)=0.044, p=0.965, \omega^{2} \leq 0.001\right)$.

Thus, two-factor repeated measures ANOVAs were conducted to examine differences in the development of ASCs between the EG and BG. There is a significant difference in the ASC development between EG and BG for all four disciplines, albeit with small to medium effect sizes (biology: $F(1,200)=9.892, p=0.002, \eta_{\mathrm{p}}{ }^{2}=0.047$; chemistry: $F(1,200)=10.871, p \leq 0.001, \eta_{\mathrm{p}}{ }^{2}=0.052$; physics: $F(1,200)=6.617, p=0.011, \eta_{\mathrm{p}}{ }^{2}=0.032$; technology: $\left.F(1,200)=18.149, p \leq 0.001, \eta_{\mathrm{p}}{ }^{2}=0.083\right)$.

In the EG, the ASC increases significantly from pre- to posttest in all four subscales with large or medium effect sizes (biology: $t=-7.272, p \leq 0.001, \eta_{\mathrm{p}}{ }^{2}=0.252$; chemistry: $t=-6.563, p \leq 0.001, \eta_{\mathrm{p}}{ }^{2}=0.215$; physics: $t=-4.879, p \leq 0.001, \eta_{\mathrm{p}}{ }^{2}=0.132$, technology: $t=-7.680, p \leq 0.001, \eta_{\mathrm{p}}{ }^{2}=0.273, n_{\mathrm{EG}}=158$ ). By contrast, the results of paired samples $t$-tests for all four ASC subscales in the BG show no significant differences between pre- and posttest means (biology: $t=-0.703, p=0.486, \eta_{\mathrm{p}}{ }^{2}=0.011$; chemistry: $t=0.090, p=0.929$, $\eta_{\mathrm{p}}{ }^{2}=0.000$; physics: $t=0.227, p=0.822, \eta_{\mathrm{p}}{ }^{2}=0.001$; technology: $t=0.728, p=0.470$, $\eta_{\mathrm{p}}{ }^{2}=0.012, n_{\mathrm{BG}}=44$ ). 
Table 3. Means (M) and standard deviations (SD) of biology-, chemistry-, physics- and technology-related ASCs at both measurement times comparing EG $(n=158)$ and BG $(n=44)$. $p$-values and effect sizes $\eta_{\mathrm{p}}{ }^{2}$ are given for inner- and intergroup comparison.

\begin{tabular}{|c|c|c|c|c|c|c|c|c|}
\hline Scale & Group & Reference Time & $\mathbf{M}$ & SD & $p$ & $\eta_{p}^{2}$ & $p_{\text {groups }}$ & $\eta_{p}$, groups ${ }^{2}$ \\
\hline \multirow{4}{*}{$\begin{array}{c}\text { biology-related } \\
\text { ASC }\end{array}$} & \multirow{2}{*}{ EG } & Pre & 3.74 & 0.90 & \multirow{2}{*}{$0.000^{* * *}$} & \multirow{2}{*}{0.252} & \multirow{4}{*}{$0.002^{* *}$} & \multirow{4}{*}{0.047} \\
\hline & & Post & 4.10 & 0.79 & & & & \\
\hline & & Pre & 3.93 & 0.75 & & & & \\
\hline & $\mathrm{BG}$ & Post & 3.98 & 0.69 & 0.486 & 0.011 & & \\
\hline \multirow{4}{*}{$\begin{array}{c}\text { chemistry-related } \\
\text { ASC }\end{array}$} & \multirow{2}{*}{ EG } & Pre & 3.02 & 1.09 & \multirow{2}{*}{$0.000^{* * *}$} & \multirow{2}{*}{0.215} & \multirow{4}{*}{$0.001^{* * *}$} & \multirow{4}{*}{0.052} \\
\hline & & Post & 3.43 & 0.99 & & & & \\
\hline & \multirow[b]{2}{*}{ BG } & Pre & 2.71 & 1.03 & \multirow[b]{2}{*}{0.929} & \multirow[b]{2}{*}{0.000} & & \\
\hline & & Post & 2.70 & 1.07 & & & & \\
\hline \multirow{4}{*}{$\begin{array}{c}\text { physics-related } \\
\text { ASC }\end{array}$} & \multirow{2}{*}{ EG } & Pre & 3.06 & 1.05 & \multirow{2}{*}{$0.000^{* * *}$} & \multirow{2}{*}{0.132} & \multirow{4}{*}{0.011 * } & \multirow{4}{*}{0.032} \\
\hline & & Post & 3.32 & 0.98 & & & & \\
\hline & \multirow{2}{*}{ BG } & Pre & 2.74 & 0.93 & \multirow{2}{*}{0.822} & \multirow{2}{*}{0.001} & & \\
\hline & & Post & 2.73 & 0.95 & & & & \\
\hline \multirow{4}{*}{$\begin{array}{c}\text { technology-related } \\
\text { ASC }\end{array}$} & \multirow{2}{*}{ EG } & Pre & 3.20 & 0.90 & \multirow{2}{*}{$0.000^{* * *}$} & \multirow{2}{*}{0.273} & \multirow{4}{*}{$0.000^{* * *}$} & \multirow{4}{*}{0.083} \\
\hline & & Post & 3.64 & 0.86 & & & & \\
\hline & & Pre & 3.19 & 0.94 & \multirow{2}{*}{0.470} & \multirow{2}{*}{0.012} & & \\
\hline & $\mathrm{BG}$ & Post & 3.12 & 0.87 & & & & \\
\hline
\end{tabular}

Significance levels: $p \leq 0.05$ significant $\left({ }^{*}\right), p \leq 0.01$ very significant $\left(^{* *}\right), p \leq 0.001$ highly significant $\left({ }^{* * *}\right)$ [203]; effect size: $0.01 \leq \eta_{p}{ }^{2}<0.06$ : Small effect, $0.06 \leq \eta_{\mathrm{p}}^{2}<0.14$ : Medium effect, $\eta_{\mathrm{p}}{ }^{2} \geq 0.14$ : Large effect [201].

\subsection{Correlations between Cognitive Gain and Changes in ASCs (RQ 2)}

Bivariate correlations were calculated between the change in CK and changes in ASCs (posttest-pretest) to evaluate the external validity of the cognitive questionnaire. The results reveal a weak, but significant positive correlation between cognitive gain and change in physics-related ASC $(r(201)=0.148 ; p=0.035)$ as well as cognitive gain and change in technology-related ASC $(r(201)=0.182 ; p=0.010)$. No significant correlations were found between change in CK and change in biology- $(r(201)=0.120 ; p=0.089)$ and chemistry-related ASC $(r(201)=0.072 ; p=0.308)$.

\subsection{Impact of the Course Format}

Having demonstrated that BG's CK and ASCs did not change significantly over time, we now examined whether the course format had an impact on cognitive gain and change in biology-, chemistry-, physics- and technology-related ASCs. Therefore, only the EG was considered for this purpose.

The impact of the factors "type of participation" (voluntary or mandatory) and "major field of studies" (SciTec or non-SciTec) was factored out as outlined in Section 2.5 to be able to attribute the effects to the influence of the course format. As described above, these factors had to be partialized out separately. Therefore, two statistical values are given for each scale and group. To improve the reading flow, the statistical values are not reported in the text. Instead, reference is made to the corresponding tables which contain the most important statistical characteristics.

\subsubsection{Content Knowledge (RQ 3.1)}

Since there were a priori differences in the test scores between weekly and block course participants, ANCOVAs were conducted for longitudinal comparisons between two groups with posttest/follow-up test scores as dependent variables, pretest scores as covariate and the variables "course format" and "type of participation" / major field of study" as fixed factors. As shown in Table 4, there is a significant difference in the increase in CK from pre- to posttest between weekly and block course participants; the effect size is medium. Short-term cognitive gain is higher among block course participants. In terms of differences in long-term gains of cognitive knowledge, the following should be noted: A 
significant difference-with a small effect size-is only given if the influence of the type of participation is factored out. There is no difference when the impact of the major field of study is factored out (see Table 4).

Table 4. Means (M) and standard deviations (SD) of declarative CK at all three measurement times comparing the groups of weekly $(n=88)$ and block format $(n=70)$ participants. $p$-values and effect sizes $\eta_{p}{ }^{2}$ are given for inner- and intergroup comparison.

\begin{tabular}{|c|c|c|c|c|c|c|c|}
\hline Group & $\begin{array}{l}\text { Reference } \\
\text { Time }\end{array}$ & $\mathbf{M}$ & SD & $p$ & $\eta_{p}^{2}$ & $p_{\text {groups }}$ & $\eta_{p}$, groups ${ }^{2}$ \\
\hline \multirow{3}{*}{ weekly } & Pre & 38.31 & 8.80 & $(0.000$ & \multirow{3}{*}{$(0.627) /[0.612]$} & \multirow{6}{*}{$\begin{array}{c}\left.\text { (Post: } 0.000^{* * *}\right), \\
\left(\text { Follow-up } 0.038^{*}\right) / \\
{\left[\text { Post } 0.000^{* * *}\right]} \\
\text { [Follow-up 0.066] }\end{array}$} & \multirow{6}{*}{$\begin{array}{c}\text { (Post 0.088), } \\
\text { (Follow-up 0.028)/ } \\
\text { [Post 0.080], } \\
\text { [Follow-up 0.022] }\end{array}$} \\
\hline & Post & 51.99 & 9.76 & $* * *) /[0.000$ & & & \\
\hline & Follow-up & 51.60 & 8.85 & $* * *]$ & & & \\
\hline \multirow{3}{*}{ block } & Pre & 34.49 & 7.93 & $(0.000$ & \multirow{3}{*}{$(0.793) /[0.793]$} & & \\
\hline & Post & 54.67 & 10.14 & $* * *) /[0.000$ & & & \\
\hline & Follow-up & 51.73 & 9.86 & $* * *]$ & & & \\
\hline
\end{tabular}

round brackets = AN(C)OVA with further between-subject factor "type of participation" (see Section 2.5); square brackets = AN(C)OVA with further between-subject factor "major field of study"; significance levels: $p \leq 0.05$ significant $\left({ }^{*}\right), p \leq 0.001$ highly significant $\left({ }^{* * *}\right)$ [203]; effect size: $0.01 \leq \eta_{\mathrm{p}}{ }^{2}<0.06$ : Small effect, $0.06 \leq \eta_{\mathrm{p}}{ }^{2}<0.14$ : Medium effect, $\eta_{\mathrm{p}}{ }^{2} \geq 0.14$ : Large effect [201]

Significant interaction effects course format ${ }^{*}$ type of participation or course format*major do not exist here, i.e., the factors "type of participation" or "major field of studies" do not additionally influence the effect of the course format on CK.

To locate the differences found, repeated measures ANOVAs were first performed for each group. The Huynh-Feldt correction was used for the subgroup of weekly participants as Mauchly's test of sphericity was significant and the Greenhouse-Geisser epsilon was $\varepsilon>0.75$. According to the ANOVA's results, both the students who attended the weekly format and those who participated in the block course showed a significant change in cognitive performance over the three measurement times; the effect was large (Table 4). Further repeated measures ANOVAs, each including two measurement time points, were then conducted for each group to more precisely localize the identified differences in the average test scores. In both subgroups, there was a significant cognitive gain from pre- to posttest and from pre- to follow-up-test (large effect size). While CK decreased significantly from post- to follow-up test in the group of block course participants (large effect), there was no significant loss of knowledge in the group of weekly participants.

\subsubsection{Academic Self-Concepts (RQ 3.2)}

With no a priori differences between the two groups regarding the four subscales, three-way repeated measures ANOVAs were conducted to examine whether the ASC development of the two groups was significantly different (factor 1/within-subject-factor: Reference time; factor 2: Course format as between-subject factor; factor 3: The factored-out between-subject factor: "Type of participation" or "major field of study"). As can be seen in Table 5, there are no statistically significant differences in the change in ASCs between the groups.

Both weekly and block course participants showed significant increases in biology-, chemistry-, physics- and technology-related ASCs from pre- to posttest (Table 5). Effect sizes are large or medium, latter with respect to the biology-related and physics-related ASC of weekly participants.

It can be concluded that both course formats lead equally to a positive change in biology-, chemistry-, physics- and technology-related ASCs of pre-service primary teachers.

No significant interaction effects time $e^{*}$ course format ${ }^{*}$ type of participation or time* course format*major field of study were observed. I.e., the factors "type of participation" or rather "major field of study" do not additionally influence the effect of the interaction time*course format on the dependent variables. The only exception is the technologyrelated ASC when factoring out the impact of the type of participation. There is a significant 
interaction effect $\left(F(1,154)=4.359, p=0.038, \eta_{\mathrm{p}}{ }^{2}=0.028\right)$, but the effect size can be described as small.

Table 5. Means (M) and standard deviations (SD) of biology-, chemistry-, physics- and technology-related ASCs at both measurement times comparing the groups of weekly $(n=88)$ and block format $(n=70)$ participants. $p$-values and effect sizes $\eta_{\mathrm{p}}{ }^{2}$ are given for inner- and intergroup comparison.

\begin{tabular}{|c|c|c|c|c|c|c|c|c|}
\hline Scale & Group & $\begin{array}{l}\text { Reference } \\
\text { Time }\end{array}$ & $\mathbf{M}$ & SD & $p$ & $\eta_{p}^{2}$ & $p_{\text {groups }}$ & $\eta_{p, \text { groups }}{ }^{2}$ \\
\hline \multirow{4}{*}{$\begin{array}{l}\text { biology- } \\
\text { related } \\
\text { ASC }\end{array}$} & \multirow{2}{*}{ weekly } & Pre & 3.74 & 0.87 & & ] 139 187) (0) & \multirow{4}{*}{$(0.442) /[0.326]$} & \multirow{4}{*}{$(0.004) /[0.006]$} \\
\hline & & Post & 4.06 & 0.77 & $\left(0.000^{* * x}\right) /\left[0.000^{* * x}\right]$ & \multirow{3}{*}{$(0.386) /[0.374]$} & & \\
\hline & \multirow{2}{*}{ block } & Pre & 3.74 & 0.93 & \multirow{2}{*}{$\left(0.000^{* * *}\right) /\left[0.000^{* * *}\right]$} & & & \\
\hline & & Post & 4.14 & 0.81 & & & & \\
\hline \multirow{4}{*}{$\begin{array}{l}\text { chemistry- } \\
\text { related } \\
\text { ASC }\end{array}$} & \multirow{2}{*}{ weekly } & Pre & 3.02 & 1.10 & \multirow{2}{*}{$\left(0.000^{* * *}\right) /\left[0.000^{* * *}\right]$} & \multirow{2}{*}{$(0.230) /[0.232]$} & \multirow{4}{*}{$(0.647) /[0.849]$} & \multirow{4}{*}{$(0.001) /[0.000]$} \\
\hline & & Post & 3.42 & 1.01 & & & & \\
\hline & \multirow{2}{*}{ block } & Pre & 3.01 & 1.08 & \multirow{2}{*}{$\left(0.000^{* * *}\right) /\left[0.000^{* * *}\right]$} & \multirow{2}{*}{$(0.225) /[0.217]$} & & \\
\hline & & Post & 3.43 & 0.97 & & & & \\
\hline \multirow{4}{*}{$\begin{array}{l}\text { physics- } \\
\text { related } \\
\text { ASC }\end{array}$} & \multirow{2}{*}{ weekly } & Pre & 3.08 & 1.09 & \multirow{2}{*}{$\left(0.000^{* * *}\right) /\left[0.000^{* * *}\right]$} & \multirow{2}{*}{$(0.133) /[0.138]$} & \multirow{4}{*}{$(0.716) /[0.528]$} & \multirow{4}{*}{$(0.001) /[0.003]$} \\
\hline & & Post & 3.38 & 1.04 & & & & \\
\hline & \multirow{2}{*}{ block } & Pre & 3.03 & 1.02 & \multirow{2}{*}{$\left(0.001^{* * *}\right) /\left[0.001^{* * *}\right]$} & \multirow{2}{*}{$(0.157) /[0.153]$} & & \\
\hline & & Post & 3.26 & 0.92 & & & & \\
\hline \multirow{4}{*}{$\begin{array}{l}\text { technology- } \\
\text { related } \\
\text { ASC }\end{array}$} & \multirow{2}{*}{ weekly } & Pre & 3.20 & 0.85 & \multirow{2}{*}{$\left(0.000^{* * *}\right) /\left[0.000^{* * *}\right]$} & \multirow{2}{*}{$(0.276) /[0.294]$} & \multirow{4}{*}{$(0.962) /[0.736]$} & \multirow{4}{*}{$(0.000) /[0.001$} \\
\hline & & Post & 3.67 & 0.88 & & & & \\
\hline & \multirow{2}{*}{ block } & Pre & 3.19 & 0.96 & \multirow{2}{*}{$\left(0.000^{* * *}\right) /\left[0.000^{* * *}\right]$} & \multirow{2}{*}{$(0.340) /[0.346]$} & & \\
\hline & & Post & 3.60 & 0.85 & & & & \\
\hline
\end{tabular}

round brackets = ANOVA with further between-subject factor "type of participation" (see Section 2.5); square brackets = ANOVA with further between-subject factor "major field of study"; significance level: $p \leq 0.001$ highly significant $\left.{ }^{* * *}\right)$ [203]; effect size: $0.01 \leq \eta_{\mathrm{p}}{ }^{2}<0.06$ : Small effect, $0.06 \leq \eta_{\mathrm{p}}{ }^{2}<0.14$ : Medium effect, $\eta_{\mathrm{p}}{ }^{2} \geq 0.14$ : Large effect [201].

\subsection{Impact of the Major Field of Study}

The intervention aims to develop the professional skills of all pre-service primary teachers, regardless of their major field of study. Thus, we also examined whether there are significant differences in the development of CK and ASCs between SciTec and non-SciTec students within the groups of participants in the weekly and block format. It was not possible to factor out the impact of the type of participation since there was a subgroup sample size of $n_{\text {non-SciTec+mandatory participation }}=0$ due to examination regulations.

\subsubsection{Content Knowledge (RQ 4.1)}

According to independent samples $t$-tests, weekly participating SciTec and non-SciTec students differed significantly in their prior $\mathrm{CK}$, the effect size being medium $(t(86)=2.565$, $p=0.012, \omega^{2}=0.060$ ). This was not the case with the block course format subgroups $\left(t(68)=1.334, p=0.187, \omega^{2}=0.012\right)$.

For the first group (weekly participants), the results of the ANCOVAs show no statistically significant differences in the change of CK from pre- to post- $(F(1,83)=0.043, p=0.836$, $\left.\eta_{\mathrm{p}}{ }^{2}=0.001\right)$ and from pre- to follow-up test $\left(F(1,83)=0.284, p=0.595, \eta_{\mathrm{p}}{ }^{2}=0.003\right)$ between SciTec and non-SciTec students.

One-way repeated measures ANOVAs with Huynh-Feldt correction (Mauchly's tests of sphericity significant and $\varepsilon>0.75$ in both subgroups) show that CK changed significantly over the three measurement times in the SciTec $(F(1.654,97.607)=88.188$, $\left.p \leq 0.001, \eta_{\mathrm{p}}{ }^{2}=0.599\right)$ and in the non-SciTec subgroup $(F(1.603,43.294)=54.761, p \leq 0.001$, $\eta_{\mathrm{p}}{ }^{2}=0.670$; Table 5). The following paired samples $t$-tests reveal a significant increase in knowledge from pre- to posttest (SciTec: $t=-9.811, p \leq 0.001, \eta_{\mathrm{p}}{ }^{2}=0.620, n=60$; nonSciTec: $t=-7.894, p \leq 0.001, \eta_{\mathrm{p}}{ }^{2}=0.698, n=28$ ) and from pre- to follow-up-test (SciTec: $t=-11.321, p \leq 0.001, \eta_{\mathrm{p}}{ }^{2}=0.685, n=60$; non-SciTec: $t=-8.169, p \leq 0.001, \eta_{\mathrm{p}}{ }^{2}=0.712$, $n=28$ ) within both subgroups. In addition, there was no loss of knowledge from post- 
to follow-up test within both subgroups (SciTec: $t=0.587, p=0.560, \eta_{\mathrm{p}}{ }^{2}=0.006, n=60$; non-SciTec: $t=0.153, p=0.880, \eta_{\mathrm{p}}{ }^{2}=0.001, n=28$ ).

These results confirm the above findings (see Section 3.3.1) and demonstrate that pre-service teachers with and without a SciTec major benefit equally from the weekly intervention in terms of short- and long-term increases in CK.

In the case of the block course subgroups, the two-way repeated measures ANOVA indicates a significant difference in the development of CK between SciTec- and non-SciTec students, with a medium effect size $\left(F(2,136)=5.610, p=0.005, \eta_{p}{ }^{2}=0.076\right.$; Table 6). Further pairwise two-way repeated ANOVAs, each with two measurement time points, served to localize the difference found. There is a significant difference in cognitive gain between preand posttest $\left(F(1,68)=9.805, p=0.003, \eta_{p}^{2}=0.126\right)$ and between pre- and follow-up test $\left(\mathrm{F}(1,68)=5.371, p=0.023, \eta_{\mathrm{p}}{ }^{2}=0.073\right)$. The effect size is medium. Thus, within the group of block course participants, short- and long-term gain of CK is greater among non-SciTec pre-service teachers (Table 6).

Table 6. Means (M) and standard deviations (SD) of declarative CK at all three measurement times comparing weekly participants with a SciTec major $(n=60)$ and a different major $(n=28)$ and block format participants with a SciTec major $(n=45)$ and a different major $(n=25)$. $p$-values and effect sizes $\eta_{\mathrm{p}}{ }^{2}$ are given for inner- and intergroup comparison.

\begin{tabular}{|c|c|c|c|c|c|c|c|c|}
\hline Group & Subgroup & Reference Time & $\mathbf{M}$ & SD & $p$ & $\eta_{p}^{2}$ & $p_{\text {groups }}$ & $\eta_{p, \text { groups }}{ }^{2}$ \\
\hline \multirow{6}{*}{ weekly } & \multirow{3}{*}{ SciTec } & Pre & 39.90 & 9.08 & \multirow{3}{*}{$0.000^{* * *}$} & \multirow{3}{*}{0.599} & \multirow{6}{*}{$\begin{array}{c}0.836 \text { (Post), } \\
0.595 \\
\text { (Follow-up) }\end{array}$} & \multirow{6}{*}{$\begin{array}{c}0.001 \text { (Post), } \\
0.003 \\
\text { (Follow-up) }\end{array}$} \\
\hline & & Post & 52.55 & 9.93 & & & & \\
\hline & & Follow-up & 52.07 & 8.99 & & & & \\
\hline & \multirow{3}{*}{ non-SciTec } & Pre & 34.89 & 7.19 & \multirow{3}{*}{$0.000^{* * *}$} & \multirow{3}{*}{0.670} & & \\
\hline & & Post & 50.79 & 9.45 & & & & \\
\hline & & Follow-up & 50.61 & 8.60 & & & & \\
\hline \multirow{6}{*}{ block } & \multirow{4}{*}{ SciTec } & Pre & 35.42 & 7.77 & & & \multirow{6}{*}{$0.005^{* *}$} & \multirow{6}{*}{0.076} \\
\hline & & Post & 53.36 & 9.98 & $0.000^{* * *}$ & 0.756 & & \\
\hline & & Follow-up & 50.87 & 9.87 & & & & \\
\hline & & Pre & 32.80 & 8.08 & & & & \\
\hline & \multirow[t]{2}{*}{ non-SciTec } & Post & 57.04 & 10.20 & $0.000^{* * *}$ & 0.842 & & \\
\hline & & Follow-up & 53.28 & 9.86 & & & & \\
\hline
\end{tabular}

Significance levels: $p \leq 0.01$ very significant $\left.{ }^{(* *}\right), p \leq 0.001$ highly significant ${ }^{(* * *}$ [203]; effect size: $0.01 \leq \eta_{\mathrm{p}}{ }^{2}<0.06$ : Small effect, $0.06 \leq$ $\eta_{\mathrm{p}}{ }^{2}<0.14$ : Medium effect, $\eta_{\mathrm{p}}{ }^{2} \geq 0.14$ : Large effect [201].

Despite these significant differences, one-way repeated measures ANOVAs show that knowledge changed within the three measurement times in both subgroups (SciTec: $F(2,88)=136.562, p \leq 0.001, \eta_{\mathrm{p}}{ }^{2}=0.756$; non-SciTec: $\left.F(2,48)=127.873, p \leq 0.001, \eta_{\mathrm{p}}{ }^{2}=0.842\right)$. CK increased significantly from pre- to posttest (SciTec: $t=-15.588, p \leq 0.001, \eta_{\mathrm{p}}{ }^{2}=0.847$, $n=45$; non-SciTec: $\left.t=-13.946, p \leq 0.001, \eta_{\mathrm{p}}{ }^{2}=0.890, n=25\right)$ and from pre- to follow-up test (SciTec: $t=-12.369, p \leq 0.001, \eta_{\mathrm{p}}{ }^{2}=0.777, n=45$; non-SciTec: $t=-11.020, p \leq 0.001$, $\left.\eta_{\mathrm{p}}{ }^{2}=0.835, n=25\right)$ in the SciTec- as well as in the non-SciTec subgroup.

A significant difference in loss of knowledge from post- to follow-up test between both subgroups could not be identified $\left(F(1,68)=0.518, p=0.474, \eta_{\mathrm{p}}{ }^{2}=0.008\right)$. According to paired samples $t$-tests, knowledge in both groups decreased significantly from post- to follow-up test with medium and high effect sizes, respectively (SciTec: $t=2.214, p=0.032$, $\eta_{\mathrm{p}}{ }^{2}=0.100, n=45$; non-SciTec: $\left.t=3.059, p=0.005, \eta_{\mathrm{p}}{ }^{2}=0.281, n=25\right)$.

\subsubsection{Academic Self-Concepts (RQ 4.2)}

Within the group of weekly participants, an independent samples $t$-test revealed pretest equality between SciTec and non-SciTec students only for the biology-related ASC $\left(t(86)=1.320, p=0.190, \omega^{2}=0.008\right)$. On the other hand, within the block course group, no pretest differences between the two subgroups were found for the biology-related $\left(t(68)=1.045, p=0.300, \omega^{2}=0.001\right)$, chemistry-related $\left(t(68)=1.718, p=0.090, \omega^{2}=0.028\right)$ and physics-related $\left(t(68)=1.753, p=0.084, \omega^{2}=0.030\right)$ ASC. In this case, two-way measures ANOVAs were performed next. 
Regarding the chemistry- $\left(t(86)=3.806, p \leq 0.001, \omega^{2}=0.133\right)$, physics- $(t(86)=4.893$, $\left.p \leq 0.001, \omega^{2}=0.207\right)$ and technology-related $\left(t(86)=6.670, p \leq 0.001, \omega^{2}=0.331\right)$ ASCs of weekly participants and the technology-related ASC within the block course group $\left(t(68)=6.286, p \leq 0.001, \omega^{2}=0.365\right)$, a priori differences were revealed between SciTec- and non-SciTec students. Because of these pretest differences, ANCOVAs were performed with pretest values as the covariate.

The results of the analyses show no significant differences in the development of the ASCs between the subgroups (Table 7). This means that both groups of pre-service primary teachers benefited equally from taking the course in terms of ASC development. With one exception, paired samples $t$-tests revealed significant increases in biology- $\left(\mathrm{SciTec}_{\text {weekly }}\right.$ : $t=-4.151, p \leq 0.001, \eta_{\mathrm{p}}{ }^{2}=0.226, n=60$; SciTec block: $t=-6.069, p \leq 0.001, \eta_{\mathrm{p}}{ }^{2}=0.456$, $n=45$; non-SciTec block $\left._{1}: t=-3.343, p=0.003, \eta_{\mathrm{p}}{ }^{2}=0.318, n=25\right)$, chemistry- $\left(\right.$ SciTec $_{\text {weekly }}$ : $t=-3.784, p \leq 0.001, \eta_{\mathrm{p}}{ }^{2}=0.195, n=60$; non-SciTec $_{\text {weekly }}: t=-3.414, p=0.002, \eta_{\mathrm{p}}{ }^{2}=0.302$, $n=28$; SciTec block $_{1}: t=-4.282, p \leq 0.001, \eta_{\mathrm{p}}{ }^{2}=0.294, n=45$; non-SciTec block $: t=-2.351$, $\left.p=0.027, \eta_{\mathrm{p}}{ }^{2}=0.187, n=25\right)$, physics- $\left(\mathrm{SciTec}_{\text {weekly }}: t=-2.333, p=0.023, \eta_{\mathrm{p}}{ }^{2}=0.084\right.$, $n=60$; non-SciTec ${ }_{\text {weekly }}: t=-3.173, p=0.004, \eta_{\mathrm{p}}^{2}=0.272, n=28$; SciTec block: $t=-2.667$, $p=0.011, \eta_{\mathrm{p}}{ }^{2}=0.139, n=45$; non-SciTec block$\left.: t=-2.156, p=0.041, \eta_{\mathrm{p}}{ }^{2}=0.162, n=25\right)$ and technology-related $\left(\right.$ SciTec $_{\text {weekly }}: t=-3.628, p \leq 0.001, \eta_{\mathrm{p}}{ }^{2}=0.182, n=60$; non-SciTec $_{\text {weekly }}$ : $t=-5.726, p \leq 0.001, \eta_{\mathrm{p}}{ }^{2}=0.548, n=28$; SciTec ${ }_{\text {block }}: t=-3.697, p \leq 0.001, \eta_{\mathrm{p}}{ }^{2}=0.237$, $n=45$; non-SciTec block: $t=-3.973, p \leq 0.001, \eta_{\mathrm{p}}{ }^{2}=0.397, n=25$ ) ASCs in all four subgroups with high or medium effect sizes, respectively. There is no statistically significant change in the biology-related ASC from pre- to posttest in the group of non-SciTec pre-service teachers, who took part in the weekly course format $(t=-1.675 ; p=0.106, n=28$; Table 7$)$.

Table 7. Means (M) and standard deviations (SD) of biology-, chemistry-, physics- and technology-related ASCs at both measurement times comparing weekly participants with a SciTec major $(n=60)$ and a different major $(n=28)$ and participants of the block format with a SciTec major $(n=45)$ and a different major $(n=25)$. $p$-values and effect sizes $\eta_{p}{ }^{2}$ are given for inner- and intergroup comparison.

\begin{tabular}{|c|c|c|c|c|c|c|c|c|c|}
\hline Scale & Group & Subgroup & $\begin{array}{l}\text { Reference } \\
\text { Time }\end{array}$ & $\mathbf{M}$ & SD & $p$ & $\eta_{p}^{2}$ & $p_{\text {groups }}$ & $\eta_{p, \text { groups }}{ }^{2}$ \\
\hline \multirow{8}{*}{$\begin{array}{l}\text { biology- } \\
\text { related } \\
\text { ASC }\end{array}$} & \multirow{4}{*}{ weekly } & \multirow{3}{*}{ SciTec } & Pre & 3.82 & 0.88 & & & \multirow{4}{*}{0.365} & \multirow{4}{*}{0.010} \\
\hline & & & Post & 4.19 & 0.76 & 0.000 & 0.226 & & \\
\hline & & & Pre & 3.56 & 0.85 & \multirow{2}{*}{0.106} & \multirow{2}{*}{0.094} & & \\
\hline & & non-SciTec & Post & 3.79 & 0.72 & & & & \\
\hline & \multirow{4}{*}{ block } & \multirow[b]{2}{*}{ SciTec } & Pre & 3.83 & 0.81 & \multirow{2}{*}{$0.000^{* * *}$} & \multirow{2}{*}{0.456} & \multirow{4}{*}{0.870} & \multirow{4}{*}{0.000} \\
\hline & & & Post & 4.22 & 0.65 & & & & \\
\hline & & \multirow[b]{2}{*}{ non-SciTec } & Pre & 3.59 & 1.11 & \multirow[b]{2}{*}{0.003 ** } & \multirow[b]{2}{*}{0.318} & & \\
\hline & & & Post & 4.00 & 1.04 & & & & \\
\hline \multirow{8}{*}{$\begin{array}{l}\text { chemistry- } \\
\text { related } \\
\text { ASC }\end{array}$} & \multirow{4}{*}{ weekly } & \multirow{3}{*}{ SciTec } & Pre & 3.31 & 1.04 & \multirow{2}{*}{$0.000^{* * *}$} & \multirow{2}{*}{0.195} & \multirow{4}{*}{0.473} & \multirow{4}{*}{0.006} \\
\hline & & & Post & 3.65 & 0.97 & & & & \\
\hline & & & Pre & 2.42 & 0.97 & \multirow{2}{*}{$0.002^{* *}$} & \multirow{2}{*}{0.302} & & \\
\hline & & non-Scilec & Post & 2.93 & 0.93 & & & & \\
\hline & \multirow{4}{*}{ block } & \multirow{2}{*}{ SciTec } & Pre & 3.18 & 1.04 & \multirow{2}{*}{$0.000 * * *$} & \multirow{2}{*}{0.294} & \multirow{4}{*}{0.255} & \multirow{4}{*}{0.019} \\
\hline & & & Post & 3.51 & 0.96 & & & & \\
\hline & & & Pre & 2.72 & 1.12 & & & & \\
\hline & & non-SciTec & Post & 3.29 & 1.01 & $0.027^{*}$ & 0.187 & & \\
\hline & & & Pre & 3.43 & 0.96 & & & & \\
\hline & & SciTec & Post & 3.67 & 0.94 & $0.023^{*}$ & 0.084 & & \\
\hline & weekıy & & Pre & 2.35 & 0.99 & & & 0.310 & 0.012 \\
\hline physics- & & non-SciTec & Post & 2.75 & 0.97 & $0.004^{* *}$ & 0.272 & & \\
\hline ASC & & & Pre & 3.19 & 0.99 & & (130 & & \\
\hline & & Scilec & Post & 3.36 & 1.01 & $0.011^{*}$ & 0.139 & & \\
\hline & block & & Pre & 2.75 & 1.03 & & & 0.320 & 0.019 \\
\hline & & non-scilec & Post & 3.07 & 0.68 & $0.041^{\star}$ & 0.162 & & \\
\hline
\end{tabular}


Table 7. Cont.

\begin{tabular}{|c|c|c|c|c|c|c|c|c|c|}
\hline Scale & Group & Subgroup & $\begin{array}{l}\text { Reference } \\
\text { Time }\end{array}$ & $\mathbf{M}$ & SD & $p$ & $\eta_{p}^{2}$ & $p_{\text {groups }}$ & $\eta_{p, \text { groups }}{ }^{2}$ \\
\hline \multirow{2}{*}{$\begin{array}{l}\text { technology- } \\
\text { related } \\
\text { ASC }\end{array}$} & weekly & SciTec & $\begin{array}{l}\text { Pre } \\
\text { Post } \\
\text { Pre } \\
\text { Post }\end{array}$ & $\begin{array}{l}3.54 \\
3.92 \\
2.48 \\
3.13\end{array}$ & $\begin{array}{l}0.70 \\
0.77 \\
0.68 \\
0.85\end{array}$ & $\begin{array}{l}0.001^{* * *} \\
0.000^{* * *}\end{array}$ & $\begin{array}{l}0.182 \\
0.548\end{array}$ & 0.336 & 0.012 \\
\hline & block & $\begin{array}{c}\text { SciTec } \\
\text { non-SciTec }\end{array}$ & $\begin{array}{l}\text { Pre } \\
\text { Post } \\
\text { Pre } \\
\text { Post }\end{array}$ & $\begin{array}{l}3.62 \\
3.86 \\
2.41 \\
3.13\end{array}$ & $\begin{array}{l}0.70 \\
0.72 \\
0.88 \\
0.89\end{array}$ & $\begin{array}{l}0.001^{* * *} \\
0.001^{* * *}\end{array}$ & $\begin{array}{l}0.237 \\
0.397\end{array}$ & 0.660 & 0.003 \\
\hline
\end{tabular}

Significance levels: $p \leq 0.05$ significant $\left({ }^{*}\right), p \leq 0.01$ very significant $\left({ }^{* *}\right), p \leq 0.001$ highly significant $\left({ }^{* * *}\right)$ [203]; effect size: $0.01 \leq \eta_{\mathrm{p}}{ }^{2}<0.06$ : Small effect, $0.06 \leq \eta_{\mathrm{p}}{ }^{2}<0.14$ : Medium effect, $\eta_{\mathrm{p}}{ }^{2} \geq 0.14$ : Large effect [201].

\section{Discussion}

In this study, the impact of an interdisciplinary university course on pre-service primary school teachers' CK and ASCs in science and technology has been examined. This is intended to contribute to providing learning environments that inherently hold the potential to foster professional knowledge and motivational orientations concerning multiple disciplines-in this case, biology, chemistry, physics and technology—simultaneously. Not only does this take into account the interdisciplinary nature of General Studies [3], but it may also be a possible solution to making the most profitable use of the limited time often allotted to this broad subject in university teacher education $[43,44]$.

\subsection{The Intervention's Impact on Pre-Service Primary Teachers' CK and ASCs \\ 4.1.1. Cognitive Gain}

Consistent with previous studies [22-28] the pretest results indicate rather low declarative CK of pre-service primary teachers in science and technology. Regarding the relevance of teachers' CK for the development of PCK and the teaching activities $[55,58,68]$ as well as the difficulty level of the items, a dilemma of primary teacher education becomes apparent. Theoretically, all questions of the test could be answered correctly by the participants already in the pretest, since they correspond to the secondary school level according to the analysis of the textbooks (see Section 2.4.1). Since this is not the case, it can be assumed that some university courses suppose basic CK that is not available at all. How can possible alternative conceptions of children be analyzed and discussed in a seminar if the pre-service teachers do not have the CK to even recognize these misconceptions? Do lecturers go over this and directly teach university-level CK, or do they invest time to help pre-service teachers refresh CK at secondary school level, which is—according to [94] - the level of CK that they will need for their professional practice? The latter objective is pursued by the present intervention.

In contrast to the BG, there are short- and long-term gains in the EG in terms of substantive, declarative CK in science and technology (RQ 1.1). Course design took into account previous findings on learning environments that have led to gain in $\mathrm{CK}$, such as content focus [102,103] and a moderate constructivist setting [106]. Making assumptions before conducting the experiment or mind-mapping at the beginning of the course activate prior knowledge that can be referred to during the course and reflected upon through the activities. Follow-up studies could investigate, among other things, whether omitting mind-mapping results in even lower CK scores in the pretest. Other factors that may have led to an increase in knowledge include: Study materials to refresh or reinforce CK (one-page texts), debrief in plenary to clarify ambiguities or questions and application of CK in planning experiment-based science/technology lessons (see Section 2.2).

Due to the interdisciplinary nature of many questions, a division according to the four disciplines was dispensed with in the evaluation. Similar to the study by Niermann [144], a test could also be used in the future in which the items can be clearly assigned to a discipline. 
However, this would not meet the interdisciplinary course concept and the requirements regarding an interdisciplinary mindset of General Studies teachers [13]. Another, more open way to investigate cross-linked CK would be the concept mapping method, which was used in the study of [102]. The validity of the knowledge test and the generalizability of the results are discussed in Section 4.4., also with the help of the interpretation of the results for RQ 2.

\subsubsection{Science- and Technology-Related Academic Self-Concepts}

So far, it has been an open question whether pre-service primary teachers differentiate between different domains of science (biology, chemistry, physics) respectively General Studies (science, technology, history, geography and politics) in their ASCs. For school context, it has been found that pupils differentiate between related (sub-)domains and content areas within a subject [121,204,205]. Gabriel-Busse et al. [121] showed that, despite multi-perspective teaching practice of General Studies, German primary school children develop five subject-specific ASCs (science, technology, history, geography and politics) that can be empirically distinguished from one another. Science domain-specific ASCs were not found. According to the results of the factor analysis, participants of this study do not have a "general" scientific-technical ASC or, for example, a science ASC and a technology ASC. Instead, they distinguish between their abilities in biology, chemistry, physics and technology, both in the pre- and posttest. These findings could result from the fact that in most German secondary schools, these four subjects are traditionally taught separately and not interdisciplinarily as in other countries [205]. Moreover, many General Studies courses at university only relate to one of these subjects [43]. Different performance experiences in these subjects lead to a differentiation of ASCs, with contrast effects also playing a role [206]. As in previous studies [32,33], the biology-related ASC is rated highest, whereas the chemistry- and physics-related ASC is rated lowest.

Factor cross-loadings of $\lambda \geq 0.30$ arising in the rotated factor matrix of the posttest data for factor 3 (physics-related ASC) and factor 4 (technology-related ASC; see Table A3) might be an indication that participating in an integrative educational setting leads to change in the ASC structure. The intervention emphasizes connections between the disciplines and focuses on interdisciplinary competencies such as problem-solving skills needed for experimentation (Section 2.2). In an interdisciplinary setting, contrast effects and the use of dimensional reference norms [114,134,206] may therefore play a minor role in affecting the ASC. Jansen et al. [204] also found that the learning environment can influence ASC structures: Correlations between the three ASC subscales biology, chemistry and physics were significantly higher in the group of ninth-grade students who were taught science in an integrated subject for several years, compared to students who were taught the three sciences separately. Subsequent longitudinal studies should therefore investigate the structural stability [110] of pre-service primary teachers' ASCs. Moving toward a "general scientific-technical ASC" by attending several interdisciplinary courses may be evidence of more coherent thinking. This would meet both the goals of General Studies, being an integrative subject $[3,45]$, and the recommendations recorded in the qualification model concerning teacher education for General Studies [13].

The results of our study indicate that a single course has the potential to reinforce pre-service primary teachers' ASC in multiple science and technology domains (RQ 1.2). While in the EG, ASC increased significantly in all four subscales from pre- to posttest with high effect sizes, there were no changes in ASCs in the BG. Comparing the change in ASCs between the two groups, the difference is significant, but the effect sizes are small to moderate. This may be due to the unequal size of the comparison groups since this can affect effect size [195]. A follow-up study with a larger sample, especially with regard to the BG, should therefore investigate whether this positive trend is confirmed. If follow-up studies confirm these small to moderate effects, the results should lead to the conclusion that such one-semester intervention does indeed have a small or moderate impact on ASC development (although not a large effect). 
Looking at the results of previous studies, it can be assumed that the interdisciplinary character of the intervention plays an essential role in the positive development of ASCs: While in the work of $[119,147]$ physics-related and technology-related ASCs, respectively, did not change significantly through courses that addressed only one domain at a time, pre-service teachers' science-related ASCs increased during a program of study with several modules integrating science [32]. In Janssen's study [120], assessing the effects of a one-semester seminar integrating biology and chemistry, the chemistry-related ASC of pre-service primary teachers also developed positively. Future studies should investigate whether participants' domain-specific ASCs remain stable at the posttest level over the course of the study, similar to [32], or whether they change due to the influence of other courses or practical experience at school.

The following course activities or components may have resulted in the positive development of participants' ASCs: By independently acquiring CK through experimentation and applying professional knowledge when planning lessons, they can experience their competencies and gain positive learning experiences $[108,110,135]$. A positive, supportive learning atmosphere, mentioned by participants in the open-ended responses [171], is also cited in the literature as a factor influencing self-concept [110]. Verbal feedback during the work phases, written feedback on the planning products $[135,136]$ and the debriefing phases promote reflection on own competencies. These continuous feedback structures and the comparison with requirements, such as the learning objectives of the course (criterial reference norm, [110]), help to assess one's state of performance. Using temporal comparisons [110,133], participants may find that they have more science and technology $\mathrm{CK}$ at the end of the course than at the beginning. The influence of grades, which are also frequently used as a source for performance evaluation [123,207], can be excluded since these were not assigned during the survey period. In addition, by anonymizing the written feedback by the lecturer and setting objective feedback criteria, we tried to minimize the negative effects of social comparisons $[16,112,133]$.

\subsection{Impact of the Course Format}

This study contributes to filling the research gaps in the field of higher education regarding the impact of course format (RQ 3 ) on students' development of professional competencies [153].

Our findings are in line with the majority of previous research showing that block courses lead to equal or even better knowledge gains than weekly courses [155-157,159,160]. The significantly higher short-term cognitive scores of the block course participants could be related to the fact that the course was not interrupted by other courses due to its format and position in the lecture-free period. This can lead to less stress [208], a more positive learning atmosphere [209], a higher level of concentration on the learning content, a more continuous learning experience and a more intense and more efficient mental linking of the contents in comparison to the weekly format $[148,158,210,211]$.

However, it is more important to examine the differences in terms of long-term $\mathrm{CK}$ retention, as "retention is considered the more serious test because it shows which knowledge is retained or stable over longer time periods" ([170], p. 21). If it turns out that block course participants lose a lot of CK from the course after six months, it is questionable to offer this course format, as it usually still takes time for them to apply the knowledge in professional practice. Again, there are slight advantages for block course participants, but only with small effect sizes and only when the type of participation is factored out. Future studies need to investigate whether this outcome is also observed when the variables "type of participation" and "major field of study" are simultaneously partialized out. In this study, this was not possible due to existing examination regulations, according to which non-SciTec students cannot be obliged to attend the course.

Besides, it is striking that among the weekly group, the CK remained stable from the post to the follow-up test, while the knowledge of the block course participants decreased significantly. In terms of long-term knowledge gain, participants of the weekly format could 
benefit from learning less content at once, which they can process and deepen gradually over weeks $[148,165,166]$. Follow-up studies covering a longer observation period than two months after the end of the course could provide further evidence for this.

Similar to Bateson's results [167], block course participants have an advantage in shortterm CK gain, but there are no differences between the groups in ASC change between the pretest and posttest. Both course formats are equally beneficial to the positive development of science- and technology-related ASCs. Thus, the period over which a course runs (a semester, i.e., several months, as opposed to four days) does not appear to be a determining factor in the development of pre-service teachers' ASCs in this case. The trends observed in the studies by $[154,159]$ (see Section 1.3) are not supported by our findings.

\subsection{Impact of the Major Field of Study}

One of the important things to consider when examining the effects of different course formats is the pre-existing knowledge of the participants, as this can have an impact on learning success [151]. Based on previous studies, showing that primary teachers with a science background have a higher science CK than those without a science major [22,45], it was assumed that non-SciTec students would have lower science and technology CK than SciTec students at pretest. This has been confirmed only for the group of weekly participants. In the block format group, CK of the non-SciTecs was also lower in the pretest but did not differ significantly from that of the SciTecs. One possible reason for these differences could be Burton and Nesbit's [151] finding that students who are more confident in a subject are more likely to choose the block format. This also matches the results that the pretest ASCs of the weekly non-SciTec participants were significantly lower than those of the SciTec students in three subscales, whereas this was the case in the block format group in only one subscale (see Section 3.4.2). Burton and Nesbit's thesis, however, is refuted when the pretest CK scores of the weekly and the block course participants are considered more globally. The scores of both SciTecs and non-SciTecs who attend weekly are each comparatively higher than those of block course participants. In future studies, the number of participants per subgroup should be as similar and as large as possible because unequal study group sizes and sample size affect test power and effect size [195].

Overall, while controlling for pretest scores using ANCOVAs when necessary, both pre-service teachers with and without a SciTec major benefit from the course in terms of CK and ASC, regardless of whether they attend weekly or the block course (RQ 4). Regarding the ASC, the intervention seems to include situations and factors that lead to a positive development of science- and technology-related ASC for both groups of pre-service teachers (see Section 4.1.2). With a heterogeneous learning group and an instructional setting that thrives on interaction with one another (see Section 2.2), social comparisons $[16,112,117,133]$ are also expected to have an impact on ASC. In addition to the aforementioned attempt to avoid the negative effects of social comparisons, non-SciTecs may have found that their knowledge and skills in science and technology are similar when compared to SciTec students.

In line with the findings of $[137,138]$, however, the comparison of short- and long-term CK gains within the block course group also demonstrates that the major field of study can be a factor influencing ASC development. The combination of a course format that has hitherto been little represented in university teaching with learning content from areas that are rarely or completely untouched in one's studies may be one of the reasons why non-SciTecs show a significantly higher increase in knowledge.

\subsection{Limitations and Implications for Further Research}

Due to the existing examination regulations, many of the pre-service teachers attended the course voluntarily. It can be assumed that mainly those interested in such training participated in the intervention. According to Richter [212], teachers who already have a higher CK level are more likely to attend professional training. Participants could also choose the course format they prefer. Thus, in subsequent studies, randomized assignment 
of pre-service teachers to the groups (EG/BG and weekly/block) would be appropriate. Otherwise, differences in the outcomes could already be due to self-selection. However, such an experimental design is often difficult to implement in regular university teaching under the given examination regulations. Burton and Nesbit also point out that "random assignment of students to traditional or block classes is unlikely to be acceptable to students, ethics committees or to universities, given the normal practice of allowing students to choose between available alternatives" ([151], p. 6).

As mentioned above, in addition to increasing the sample size per subgroup, the stability of CK and ASC over a longer period than two months after the end of the course should be examined to better assess the sustainability of the intervention.

Regarding the cognitive questionnaire, the following limitations should be noted: CK is domain-specific [213]. That is, a high CK in one topic (e.g., human respiratory system) does not necessarily imply high CK in another topic (e.g., human senses). Even though the questionnaire covers several topics from science and technology, only course-specific content is assessed, which limits the generalizability of the results. The same applies to the type of knowledge. In future studies, not only the development of declarative CK but also that of procedural or situational CK could be investigated, as these are also relevant for professional action [54]. In preparing the analysis of the cognitive test, we were also confronted with a reliability-validity trade-off [214]: A broad coverage of the knowledge under investigation usually increases validity, but this may lead to low reliability of the test. We tried to find a balance by using a test that represents a wide variety of topics and by choosing a low discriminability value that led to the exclusion of items, as is recommended for broad constructs [195]. Nevertheless, several items had to be removed, which on the one hand led to acceptable reliability (see Section 2.5), but on the other hand, may result in lower validity. Referring to the findings of Paulick and colleagues [116], our study tested the validity of the knowledge test by correlating CK increases with changes in ASCs (RQ 2). The more the participants gained CK, the more their physics- and technology-related self-concept increased. No significant correlations were found for the biology- and chemistry-related ASCs. These results can be interpreted to the effect that the questionnaire - after removal of the items according to the above criteria—adequately covers the CK in the disciplines of physics and technology and that there is further need for optimization for the disciplines of biology and chemistry. This need is alleviated when the results on correlations with the external criterion "last school grade" are added. Here, weak but significant correlations were found between CK posttest scores and school grades in biology, chemistry and physics. As with [72], high school GPA (grade point average) could additionally be used for external testing of knowledge test's validity in the future.

As an online questionnaire was used, it cannot be ruled out that participants relied on external help to answer the questions, even if they were asked not to do so. Due to the anonymity of the test and the lack of an examination character, it was not expected that external help would be used. The instrument "online questionnaire" was deliberately chosen because it offers many advantages: There are more ways to present the questions, resource consumption is less, and with open-ended answers, there is no difficulty deciphering the handwriting. Missing values are reduced because participants are alerted to missing responses, and data entry time and errors are minimized as data no longer need to be entered manually by the person conducting the evaluation. The primary reason, though, was that it would otherwise have been difficult to reach participants for the follow-up test two months after the end of the course.

In this study, the instructor of the intervention was also the researcher. The influence of this confounding variable [215] was minimized by considering several aspects of course delivery, data collection and data analysis: The effect of "teaching to the test" was avoided by the course setting, which emphasized self-directed knowledge acquisition through experimentation, and by the abundance of supplementary material provided after the experiments (see Section 2.2). To ensure objectivity in conducting the study [195], the links to the online questionnaires were always sent by the same test administrator with the same 
instructions and information via the digital message forum in all course runs. Objectivity of data analysis was ensured by using a predominantly closed-response format, a scoring key for the open-ended responses in the cognitive test and a standardized data analysis procedure (see Section 2.5). Since CK alone is not sufficient ensure to lead to effective instruction or to improve pupil achievement $[60,216]$ future studies should also consider the intervention's impact on pre-service teachers' PCK. It could be explored, for example, whether attending the course reinforces pre-service teachers' PCK about primary school children's (alternative) conceptions of course topics. Referring to the finding that CK is negatively correlated with PCK self-concept [117], we could also examine whether gains in CK lead pre-service teachers to have more pessimistic perceptions of their PCK.

\section{Conclusions}

In summary, this study shows that a single interdisciplinary university course holds the potential to positively impact not only pre-service primary teachers' CK but also their ASC in several disciplines. Thus, interdisciplinary interventions of this kind could be one way of addressing the challenges facing the primary teacher education system worldwide (see introduction). The course concept has been proven to be suitable for a heterogeneous learner population. The finding that the course format can significantly influence the CK is relevant not only to the design of university curricula and courses but also to the offering of voluntary professional development courses in teacher education.

Author Contributions: Conceptualization, research design, methodology, data collection, validation, data analysis, visualization, writing —original draft, funding acquisition, M.M.B.; supervision, data analysis, writing - review and editing, K.D.; supervision, conceptualization and funding acquisition, A.P. All authors have read and agreed to the published version of the manuscript.

Funding: This work was funded by the "Qualitätsoffensive Lehrerbildung", a joint initiative of the Federal Government and the Länder, which aims to improve the quality of teacher training. The program is funded by the Federal Ministry of Education and Research (BMBF). The authors are responsible for the content of this publication; grant number 0JA1507. We gratefully acknowledge the support of the Open Access Publication Fund of the University of Wuppertal (grant number: GoldOA-PUBL20210923).

Institutional Review Board Statement: Ethical review and approval were waived for this study because, according to the German legislation on research involving human subjects, ethical approval is only required when sensitive data are collected, when physical interventions are performed, or when subjects could be harmed. Before the start of the study, all participants were informed of the aims of the study, that participation was voluntary, that by completing the questionnaire they were giving their consent to participate voluntarily, that participation could be discontinued at any time, and that full anonymity was guaranteed.

Informed Consent Statement: Informed consent was obtained from all subjects involved in the study.

Data Availability Statement: The data presented in this study are available on request from the corresponding author.

Conflicts of Interest: The authors declare no conflict of interest. The funders had no role in designing the study, in data collection, in analyzing and interpreting the data, or in writing the manuscript. 


\section{Appendix A}

Table A1. Examples of textbooks and handouts used to ensure the curricular validity of the cognitive questionnaire.

\begin{tabular}{ccc}
\hline Topic (Subtopic) & Content Level & Reference \\
\hline & primary school & {$[217,218]$} \\
Bionics (Lotus effect) & secondary school & {$[219,220]$} \\
& university & {$[221-224]$} \\
\hline \multirow{2}{*}{ The human body (air and } & primary school & {$[225-229]$} \\
respiratory system) & secondary school & {$[230-232]$} \\
& university & {$[233-236]$} \\
\hline
\end{tabular}

Table A2. Sample questions (cognitive questionnaire).

\begin{tabular}{|c|c|c|c|c|c|}
\hline $\begin{array}{l}\text { Original Question with } \\
\text { Corresponding Items }\end{array}$ & $\begin{array}{l}\text { Translation of Sample } \\
\text { Question with } \\
\text { Corresponding Items }\end{array}$ & $\begin{array}{l}\text { Type of } \\
\text { Question }\end{array}$ & Disciplines & Content Level & $\begin{array}{l}\text { Complexity } \\
\text { Level }\end{array}$ \\
\hline $\begin{array}{l}\text { Es geht nun um die } \\
\text { Phasenübergänge } \\
\text { zwischen den } \\
\text { Aggregatzuständen fest, } \\
\text { flüssig und gasförmig. } \\
\text { Geben Sie die } \\
\text { Bezeichnung (ein Wort } \\
\text { genügt, z.B. “Schmelzen”) } \\
\text { für die genannten } \\
\text { Vorgänge an. Falls Sie es } \\
\text { nicht wissen, setzen Sie } \\
\text { ein Fragezeichen (?). } \\
\text { - fest zu gasförmig: } \\
\text { - } \quad \overline{\text { flüssig zu fest: }} \\
\text { - gasförmig zu flüssig: } \\
\text { - } \overline{\text { flüssig zu gasförmig: }} \\
\quad-\end{array}$ & $\begin{array}{l}\text { It is now about the phase } \\
\text { transitions between the } \\
\text { physical states of matter } \\
\text { (solid, liquid, and gas). } \\
\text { Enter the term (one word } \\
\text { is sufficient, e.g., } \\
\text { "melting") for the } \\
\text { processes mentioned. If } \\
\text { you don't know, put a } \\
\text { question mark (?). } \\
\text { - solid to gas: } \\
\text { - liquid to solid: } \\
\text { - gas to liquid: } \\
\text { - liquid to gas: }\end{array}$ & $\begin{array}{l}\text { open-ended } \\
\text { question }\end{array}$ & $\begin{array}{l}\text { chemistry, } \\
\text { physics }\end{array}$ & $\begin{array}{l}\text { primary school, } \\
\text { secondary } \\
\text { school (solid to } \\
\text { gas: secondary } \\
\text { school, } \\
\text { university } \\
\text { level) }\end{array}$ & fact \\
\hline $\begin{array}{l}\text { Welche dieser Geräte } \\
\text { gehören zu den } \\
\text { zweiseitigen Hebeln? } \\
\text { Kreuzen Sie alles } \\
\text { Zutreffende an! } \\
\text { - } \quad \text { Schere } \\
\text { - Wippe } \\
\text { - } \quad \text { Schubkarre } \\
\text { - } \quad \text { Nussknacker }\end{array}$ & $\begin{array}{l}\text { Which of these devices } \\
\text { belong to the two-sided } \\
\text { levers? Tick all that apply! } \\
\text { - } \quad \text { scissors } \\
\text { - } \quad \text { rocker } \\
\text { - } \quad \text { wheelbarrow } \\
\text { - nutcracker }\end{array}$ & $\begin{array}{l}\text { closed-ended } \\
\text { question }\end{array}$ & $\begin{array}{l}\text { physics, } \\
\text { technology }\end{array}$ & $\begin{array}{l}\text { secondary } \\
\text { school }\end{array}$ & relations/concepts \\
\hline
\end{tabular}


Table A2. Cont.

\begin{tabular}{|c|c|c|c|c|c|}
\hline $\begin{array}{l}\text { Original Question with } \\
\text { Corresponding Items }\end{array}$ & $\begin{array}{c}\text { Translation of Sample } \\
\text { Question with } \\
\text { Corresponding Items }\end{array}$ & $\begin{array}{l}\text { Type of } \\
\text { Question }\end{array}$ & Disciplines & Content Level & Complexity Level \\
\hline $\begin{array}{l}\text { Beim Blutdruckmessen } \\
\text { einer Ihnen unbekannten } \\
\text { Person zeigt Ihr } \\
\text { Blutdruckmessgerät } \\
\text { folgende Werte an: } \\
\text { Blutdruck: } 90 / 60 \text {. Welche } \\
\text { dieser Aussagen sind } \\
\text { dann korrekt? }\end{array}$ & $\begin{array}{l}\text { When measuring the } \\
\text { blood pressure of a person } \\
\text { you do not know, your } \\
\text { blood pressure monitor } \\
\text { shows the following } \\
\text { values: Blood pressure: } \\
90 / 60 \text {. Which of these } \\
\text { statements are correct? }\end{array}$ & $\begin{array}{l}\text { closed-ended } \\
\text { question }\end{array}$ & $\begin{array}{l}\text { biology, } \\
\text { physics }\end{array}$ & $\begin{array}{l}\text { secondary } \\
\text { school, } \\
\text { university }\end{array}$ & relations/concepts \\
\hline $\begin{array}{l}\text { Die Zahl } 90 \text { steht für } \\
\text { den systolischen } \\
\text { Blutdruck, } 60 \text { für den } \\
\text { diastolischen } \\
\text { Blutdruck. } \\
\text { Die Zahl } 90 \text { steht für } \\
\text { den diastolischen } \\
\text { Blutdruck, } 60 \text { für den } \\
\text { systolischen } \\
\text { Blutdruck. } \\
\text { Sie können ableiten, } \\
\text { dass dies der ideale } \\
\text { Blutdruck einer } 10 \\
\text { bis 30-jährigen } \\
\text { Person ist. } \\
\text { Sie können ableiten, } \\
\text { dass dies der ideale } \\
\text { Blutdruck eines } \\
\text { Kindes unter } 10 \\
\text { Jahren ist. }\end{array}$ & $\begin{array}{l}\text { The number } 90 \\
\text { stands for systolic } \\
\text { blood pressure, } 60 \\
\text { for diastolic blood } \\
\text { pressure. } \\
\text { The number } 90 \\
\text { stands for diastolic } \\
\text { blood pressure, } 60 \\
\text { for systolic blood } \\
\text { pressure. } \\
\text { You can deduce that } \\
\text { this is the ideal blood } \\
\text { pressure for a } 10-\text { to } \\
\text { 30-year-old. } \\
\text { You can deduce that } \\
\text { this is the ideal blood } \\
\text { pressure for a child } \\
\text { under } 10 \text { years of } \\
\text { age. }\end{array}$ & & & & \\
\hline
\end{tabular}

Table A3. Assignment of items to factors (rotated factor matrix) and communalities $\left(h^{2}\right)$. Loadings that led to the assignment of the variables to the factor/subscale are highlighted in gray. Factor loadings $\lambda<0.30$, interpreted as low [193], are not shown.

\begin{tabular}{|c|c|c|c|c|c|}
\hline $\begin{array}{c}\text { Item Abbreviation } \\
\text { (Pre/Post) }\end{array}$ & Factor 1 (Pre/Post) & Factor 2 (Pre/Post) & Factor 3 (Pre/Post) & Factor 4 (Pre/Post) & $h^{2}$ (Pre/Post) \\
\hline \multicolumn{6}{|l|}{$1-6$} \\
\hline TU31_03/NT19_11 & $0.689 / 0.781$ & - & - & - & $0.490 / 0.640$ \\
\hline TU31_05/NT19_01 & $0.875 / 0.896$ & - & - & - & $0.794 / 0.827$ \\
\hline TU31_08/NT19_06 & $0.832 / 0.754$ & - & - & - & $0.715 / 0.598$ \\
\hline TU31_06/NT19_05 & - & $0.878 / 0.877$ & - & - & $0.792 / 0.808$ \\
\hline TU31_11/NT19_10 & - & $0.910 / 0.910$ & - & - & $0.864 / 0.873$ \\
\hline TU31_13/NT19_12 & - & $0.887 / 0.820$ & - & - & $0.837 / 0.736$ \\
\hline TU31_09/NT19_18 & - & - & $0.846 / 0.877$ & $-/ 0.328$ & $0.784 / 0.894$ \\
\hline TU31_14/NT19_15 & - & - & $0.836 / 0.856$ & - & $0.803 / 0.817$ \\
\hline TU31_16/NT19_08 & - & - & $0.876 / 0.808$ & $-/ 0.305$ & $0.844 / 0.760$ \\
\hline TU31_02/NT19_04 & - & - & - & $0.805 / 0.896$ & $0.735 / 0.913$ \\
\hline TU31_15/NT19_14 & - & - & $0.342 / 0.361$ & $0.716 / 0.754$ & $0.641 / 0.711$ \\
\hline TU31_17/NT19_17 & - & - & $-/ 0.373$ & $0.755 / 0.680$ & $0.705 / 0.649$ \\
\hline
\end{tabular}

\section{References}

1. Bybee, R.W. Achieving Scientific Literacy. Sci. Teach. 1995, 62, $28-33$.

2. Mammes, I.; Schaper, N.; Strobel, J. Professionalism and the Role of Teacher Beliefs in Technology Teaching in German Primary Schools-An Area of Conflict. In Teachers' Pedagogical Beliefs: Definition and Operationalisation-Connections to Knowledge and Performance—Development and Change; König, J., Ed.; Waxmann: Münster, Germany, 2012; pp. 91-105. 
3. Gesellschaft für Didaktik des Sachunterrichts (GDSU). Perspektivrahmen Sachunterricht; Klinkhardt: Bad Heilbrunn, Germany, 2013.

4. National Research Council. A Framework for K-12 Science Education: Practices, Crosscutting Concepts, and Core Ideas; National Academies Press: Washington, DC, USA, 2012.

5. van den Akker, J.J.H. The Science Curriculum: Between Ideals and Outcomes. In International Handbook of Science Education; Fraser, B.J., Tobin, K.G., Eds.; Kluwer: Dordrecht, The Netherlands, 1998; pp. 421-447. [CrossRef]

6. Skolverket Sweden. Curriculum for the Compulsory School, Preschool Class and School-Age Educare 2001, Revised 2018. Available online: https: / /www.skolverket.se / getFile?file=3984 (accessed on 21 October 2021).

7. Zhengmei, P.; Shaoyang, W. Der Sachunterrichtslehrplan der chinesischen Grundschule. In Handbuch Didaktik des Sachunterrichts, 2nd ed.; Kahlert, J., Fölling-Albers, M., Götz, M., Hartinger, A., Miller, S., Wittkowske, S., Eds.; Klinkhardt: Bad Heilbrunn, Germany, 2015; pp. 304-309.

8. Lange-Schubert, K.; Hartinger, A. Lehrerkompetenzen im Sachunterricht. In Sachunterricht_Didaktik für die Grundschule, 5th ed.; Hartinger, A., Lange-Schubert, K., Eds.; Cornelsen: Berlin, Germany, 2020; pp. 26-37.

9. Shulman, L.S. Those Who Understand: Knowledge Growth in Teaching. Educ. Res. 1986, 15, 4-14. [CrossRef]

10. Shulman, L.S. Knowledge and Teaching: Foundations of the New Reform. Harv. Educ. Rev. 1987, 57, 1-23. [CrossRef]

11. Baumert, J.; Kunter, M. The COACTIV Model of Teachers' Professional Competence. In Cognitive Activation in the Mathematics Classroom and Professional Competence of Teachers: Results from the COACTIV Project; Kunter, M., Baumert, J., Blum, W., Klusmann, U., Krauss, S., Neubrand, M., Eds.; Springer: New York, NY, USA, 2013; pp. 25-48. [CrossRef]

12. Berg, T.; Brouwer, W. Teacher awareness of student alternate conceptions about rotational motion and gravity. J. Res. Sci. Teach. 1991, 28, 3-18. [CrossRef]

13. Gesellschaft für Didaktik des Sachunterrichts (GDSU). Qualitätsrahmen Lehrerbildung—Sachunterricht und Seine Didaktik; Klinkhardt: Bad Heilbrunn, Germany, 2019.

14. Blömeke, S.; Gustaffson, J.-E.; Shavelson, R.J. Beyond Dichotomies: Competence Viewed as a Continuum. Z. Psychol. 2015, 223, 3-13. [CrossRef]

15. Trautwein, U.; Möller, J. Self-Concept: Determinants and Consequences of Academic Self-Concept in School Contexts. In Psychosocial Skills and School Systems in the 21st Century. Theory, Research, and Practice; Lipnevich, A.A., Preckel, F., Roberts, R.D., Eds.; Springer International Publishing: Basel, Switzerland, 2016; pp. 187-214. [CrossRef]

16. Dickhäuser, O. Fähigkeitsselbstkonzepte-Entstehung, Auswirkung, Förderung. Z. Padagog. Psychol. 2006, 20, 5-8. [CrossRef]

17. Kleickmann, T. Professionelle Kompetenz von Primarschullehrkräften im Bereich des naturwissenschaftlichen Sachunterrichts. Z Grund. 2015, 8, 7-22.

18. Landwehr, B. Distanzen von Lehrkräften und Studierenden des Sachunterrichts zur Physik. In Eine Qualitativ-Empirische Studie zu den Ursachen; Logos: Berlin, Germany, 2002.

19. Köster, H.; von Balluseck, H.; Kraner, R. Technische Bildung im Elementar-und Primarbereich. In Technische Bildung für Alle: Ein vernachlässigtes Schlüsselelement der Innovationspolitik; Buhr, R., Hartmann, E.A., Eds.; VDI/VDE Innovation + Technik GmbH: Berlin, Germany, 2008; pp. 33-54.

20. Möller, K. Naturwissenschaftliches Lernen in der Grundschule-Welche Kompetenzen brauchen Grundschullehrkräfte? In Lehrerbildung: IGLU und die Folgen; Merkens, H., Ed.; Leske + Budrich: Opladen, Germany, 2004; pp. 65-84.

21. Yeung, A.S.; Craven, R.G.; Kaur, G. Teachers' self-concept and valuing of learning: Relations with teaching approaches and beliefs about students. Asia-Pac. J. Teach. Educ. 2014, 42, 305-320. [CrossRef]

22. Harlen, W. Primary Teachers' Understanding in Science and its Impact in the Classroom. Res. Sci. Educ. 1997, $27,323-337$. [CrossRef]

23. Kruger, C.; Summers, M. Primary School Teachers' Understanding of Science Concepts. J. Educ. Teach. 1988, 14, 259-265. [CrossRef]

24. Murphy, C.; Smith, G. The impact of a curriculum course on pre-service primary teachers' science content knowledge and attitudes towards teaching science. Ir. Educ. Stud. 2012, 31, 77-95. [CrossRef]

25. Senocak, E. Prospective Primary School Teachers' Perceptions on Boiling and Freezing. Aust. J. Teach. Educ. 2009, 34, 27-38. [CrossRef]

26. Smith, D.C.; Neale, D.C. The construction of subject matter knowledge in primary science teaching. Teach. Teach. Educ. 1989, 5, 1-20. [CrossRef]

27. Stevens, C.; Wenner, G. Elementary Preservice Teachers' Knowledge and Beliefs Regarding Science and Mathematics. Sch. Sci. Math. 1996, 96, 2-9. [CrossRef]

28. Urban-Woldron, H. Fachwissen-ein wichtiger Bestandteil des Professionswissens von Volksschullehrkräften? Eine empirische Studie zu einer Lehrveranstaltung im naturwissenschaftlichen Sachunterricht. R.E.-SOURCE 2014, 1, 36-48.

29. Appleton, K. Elementary Science Teaching. In Handbook of Research on Science Education; Abell, S.K., Lederman, N.G., Eds.; Lawrence Erlbaum: Mahwah, NJ, USA, 2007; pp. 493-535.

30. Fleer, M. Early Childhood Science Teacher Education. In Encyclopedia of Science Education; Gunstone, R., Ed.; Springer: Dordrecht, The Netherlands, 2015; pp. 347-354. [CrossRef]

31. Mant, J.; Summers, M. Some primary school teachers' understanding of the earth's place in the universe. Res. Pap. Educ. 1993, 8, 101-129. [CrossRef] 
32. Göhring, A. Naturwissenschaftlich integrierte Lehrerbildung an der Universität-Modellversuch Naturwissenschaft und Technik (NWT). In Vielperspektivität im Sachunterricht; Giest, H., Hartinger, A., Tänzer, S., Eds.; Klinkhardt: Bad Heilbrunn, Germany, 2017; pp. 201-208.

33. Pahl, A. Unterrichten von Natur und Technik in Kindergarten und Primarschule: Zu den Vorlieben von Lehramtsstudierenden. In Naturwissenschaftliche Kompetenzen in der Gesellschaft von Morgen, Proceedings of the Annual Meeting of the Society for the Principles of Teaching Chemistry and Physics (GDCP), Wien, Australia, 9 September 2019; Habig, S., Ed.; University of Duisburg-Essen: Duisburg/Essen, Germany, 2020; pp. 625-628.

34. Book, C.L.; Freeman, D.J. Differences in Entry Characteristics of Elementary and Secondary Teacher Candidates. J. Teach. Educ. 1986, 37, 47-51. [CrossRef]

35. Billich-Knapp, M.; Künstig, J.; Lipowsky, F. Profile der Studienwahlmotivation bei Grundschullehramtsstudierenden. Z. Pädagogik 2012, 58, 696-719.

36. König, J.; Rothland, M.; Darge, K.; Lünnemann, M.; Tachtsoglou, S. Erfassung und Struktur berufswahlrelevanter Faktoren für die Lehrerausbildung und den Lehrerberuf in Deutschland, Österreich und der Schweiz. Z. Erzieh. 2013, 16, 553-577. [CrossRef]

37. Trojer, P. Wer Wird Lehrer/Lehrerin? Konzepte der Berufswahl und Befunde zur Entwicklung des Berufswunsches Lehrer/in und ihre Bedeutung für das Studium; Klinkhardt: Bad Heilbrunn, Germany, 2018.

38. Weiß, S.; Braune, A.; Steinherr, E.; Kiel, E. Studium Grundschullehramt. Zur problematischen Kompatibilität von Studien/Berufswahlmotiven und Berufsvorstellungen. Z. Grund. 2009, 2, 126-138.

39. Marsh, H.W.; Yeung, A.S. Coursework selection: Relations to academic self-concept and achievement. Am. Educ. Res. J. 1997, 34, 691-720. [CrossRef]

40. Davis, E.A.; Petish, D.; Smithey, J. Challenges New Science Teachers Face. Rev. Educ. Res. 2006, 76, 607-651. [CrossRef]

41. Döhrmann, M.; Hacke, S.; Buchholz, C. Nationale und internationale Typen an Ausbildungsgängen zur Primarstufenlehrkraft. In TEDS-M 2008. Professionelle Kompetenz und Lerngelegenheiten Angehender Primarstufenlehrkräfte im Internationalen Vergleich; Blömeke, S., Kaiser, G., Lehmann, R., Eds.; Waxmann: Münster, Germany, 2010; pp. 55-71.

42. Blömeke, S.; Kaiser, G.; Lehmann, R. TEDS-M 2008 Primarstufe: Ziele, Untersuchungsanlage und zentrale Ergebnisse. In TEDS-M 2008. Professionelle Kompetenz und Lerngelegenheiten Angehender Primarstufenlehrkräfte im Internationalen Vergleich; Blömeke, S., Kaiser, G., Lehmann, R., Eds.; Waxmann: Münster, Germany, 2010; pp. 11-38.

43. Schilling, Y.; Beudels, M.; Kuckuck, M.; Preisfeld, A. Sachunterrichtsbezogene Teilstudiengänge aus NRW auf dem Prüfstand. Eine Dokumentenanalyse der Bachelor-und Masterprüfungsordnungen. HLZ 2021, 4, 178-195. [CrossRef]

44. Baumgardt, I.; Kaiser, A. Lehrer-und Lehrerinnenbildung. In Handbuch Didaktik des Sachunterrichts, 2nd ed.; Kahlert, J., Fölling-Albers, M., Götz, M., Hartinger, A., Miller, S., Wittkowske, S., Eds.; Klinkhardt: Bad Heilbrunn, Germany, 2015 ; pp. 73-82.

45. Schmidt, M. Professionswissen von Sachunterrichtslehrkräften: Zusammenhangsanalyse zur Wirkung von Ausbildungshintergrund und Unterrichtserfahrung Auf das fachspezifische Professionswissen im Unterrichtsinhalt "Verbrennung"; Logos: Berlin, Germany, 2015.

46. Riese, J.; Reinhold, R. Fachbezogene Kompetenzmessung und Kompetenzentwicklung bei Lehramtsstudierenden der Physik im Vergleich verschiedener Studiengänge. Lehr. Prüfstand 2009, 2, 104-125.

47. Porsch, R. Fachfremdes Unterrichten in Deutschland: Welche Rolle spielt die Lehrerbildung? In Professionelles Handeln im Fachfremd Erteilten Mathematikunterricht; Porsch, R., Rösken.Winter, B., Eds.; Springer Spektrum: Wiesbaden, Germany, 2020; pp. 29-47. [CrossRef]

48. Porsch, R.; Wendt, H. Aus- und Fortbildung von Mathematik-und Sachunterrichtslehrkräften. In TIMSS 2015. Mathematische und Naturwissenschaftliche Kompetenzen von Grundschulkindern in Deutschland im Internationalen Vergleich; Wendt, H., Bos, W., Selter, C., Köller, O., Schwippert, K., Kasper, D., Eds.; Waxmann: Münster, Germany; New York, NY, USA, 2016; pp. $189-204$.

49. Harada, N. Lebenskundeunterricht als integrativ-anschlussfähiges Schulfach Japans. In Handbuch Didaktik des Sachunterrichts, 2nd ed.; Kahlert, J., Fölling-Albers, M., Götz, M., Hartinger, A., Miller, S., Wittkowske, S., Eds.; Klinkhardt: Bad Heilbrunn, Germany, 2015; pp. 289-293.

50. Vogt, M. Sachunterricht in Frankreich. In Handbuch Didaktik des Sachunterrichts, 2nd ed.; Kahlert, J., Fölling-Albers, M., Götz, M., Hartinger, A., Miller, S., Wittkowske, S., Eds.; Klinkhardt: Bad Heilbrunn, Germany, 2015; pp. 279-284.

51. Meschede, N.; Hartinger, A.; Möller, K. Sachunterricht in der Lehrerinnen-und Lehrerbildung. Rahmenbedingungen, Befunde und Perspektiven. In Handbuch Lehrerinnen—und Lehrerbildung; Cramer, C., König, J., Rothland, M., Blömeke, S., Eds.; Klinkhardt: Bad Heilbrunn, Germany, 2020; pp. 541-548. [CrossRef]

52. Möller, K.; Kleickmann, T.; Lange-Schubert, K.; Todorova, M. Professionelle Kompetenz für den naturwissenschaftlichen Sachunterricht-ihre Bedeutung für Unterrichtsqualität und Möglichkeiten ihrer Förderung. In Professionelle Kompetenz von Lehrkräften der Chemie und Physik; Fischler, H., Sumfleth, E., Eds.; Logos: Berlin, Germany, 2017; pp. 157-183.

53. Grossmann, P.L. The Making of a Teacher: Teacher Knowledge and Teacher Education; Teachers College Press: New York, NY, USA, 1990.

54. Artelt, C.; Kunter, M. Kompetenzen und berufliche Entwicklung von Lehrkräften. In Psychologie für den Lehrberuf; Urhahne, D., Dresel, M., Fischer, F., Eds.; Springer: Berlin/Heidelberg, Germany, 2019; pp. 395-415. [CrossRef]

55. Baumert, J.; Kunter, M.; Blum, W.; Brunner, M.; Voss, T.; Jordan, A.; Klusmann, U.; Krauss, S.; Neubrand, M.; Tsai, Y.-M. Teachers' Mathematical Knowledge, Cognitive Activation in the Classroom, and Student Progress. Am. Educ. Res. J. 2010, 47, 133-180. [CrossRef] 
56. Grossman, P.L.; Schoenfeld, A.H.; Lee, C. Teaching subject matter. In Preparing Teachers for a Changing World: What Teachers Should Learn and Be Able to Do; Darling-Hammond, L., Bransford, J.D., Eds.; Jossey-Bass: San Francisco, CA, USA, 2005 ; pp. $201-231$.

57. Ball, D.L.; Thames, M.H.; Phelps, G. Content Knowledge for Teaching: What Makes It Special? J. Teach. Educ. 2008, 59, 389-407. [CrossRef]

58. Hashweh, M.Z. Effects of subject-matter knowledge in the teaching of biology and physics. Teach. Teach. Educ. 1987, 3, 109-120. [CrossRef]

59. Schwab, J.J. Science, Curriculum, and Liberal Education: Selected Essays; The University of Chicago Press: Chicago, IL, USA, 1978.

60. Abell, S.K. Research on science teacher knowledge. In Handbook of Research on Science Education; Abell, S.K., Lederman, N.G., Eds.; Lawrence Erlbaum: Mahwah, NJ, USA, 2007; pp. 1105-1149.

61. Grossman, P.L.; Wilson, S.M.; Shulman, L.S. Teachers of substance: Subject matter knowledge for teaching. In Knowledge Base for the Beginning Teacher; Reynolds, M.C., Ed.; Pergamon Press: Oxford, UK, 1989; pp. 23-36.

62. Abd-El-Khalick, F.; BouJaoude, S. An exploratory study of the knowledge base for science teaching. J. Res. Sci. Teach. 1997, 34, 673-699. [CrossRef]

63. Anderson, L.W.; Krathwohl, D.R. A Taxonomy for Learning, Teaching, and Assessing. A Revision of Bloom's Taxonomy of Educational Objectives; Longman: New York, NY, USA, 2001.

64. Paris, S.G.; Lipson, M.Y.; Wixson, K.K. Becoming a strategic reader. Contemp. Educ. Psychol. 1983, 8, 293-316. [CrossRef]

65. Shavelson, R.J.; Ruiz-Primo, M.A.; Wiley, E.W. Windows into the mind. High. Educ. 2005, 49, 413-430. [CrossRef]

66. Capraro, R.; Capraro, M.; Parker, D.; Kulm, G.; Raulerson, T. The Mathematics Content Knowledge Role in Developing Preservice Teachers' Pedagogical Content Knowledge. J. Res. Child. Educ. 2005, 20, 102-118. [CrossRef]

67. Depaepe, F.; Torbeyns, J.; Vermeersch, N.; Janssens, D.; Janssen, R.; Kelchtermans, G.; Verschaffel, L.; Dooren, W.V. Teachers' content and pedagogical content knowledge on rational numbers: A comparison of prospective elementary and lower secondary school teachers. Teach. Teach. Educ. 2015, 47, 82-92. [CrossRef]

68. Käpylä, M.; Heikkinen, J.-P.; Asunta, T. Influence of Content Knowledge on Pedagogical Content Knowledge: The case of teaching photosynthesis and plant growth. Int. J. Sci. Educ. 2009, 31, 1395-1415. [CrossRef]

69. Kind, V. Pedagogical content knowledge in science education: Perspectives and potential for progress. Stud. Sci. Educ. 2009, 45, 169-204. [CrossRef]

70. Ma, L. Knowing and Teaching Elementary Mathematics: Teachers' Understanding of Fundamental Mathematics in China and the United States; Lawrence Erlbaum: Hillsdale, NJ, USA, 1999. [CrossRef]

71. van Driel, J.H.; de Jong, O.; Verloop, N. The Development of Preservice Chemistry Teachers' Pedagogical Content Knowledge. Sci. Educ. 2002, 86, 572-590. [CrossRef]

72. Großschedl, J.; Harms, U.; Kleickmann, T.; Glowinski, I. Preservice Biology Teachers' Professional Knowledge: Structure and Learning Opportunities. J. Sci. Teach. Educ. 2015, 26, 291-318. [CrossRef]

73. Riese, J.; Reinhold, P. Die professionelle Kompetenz angehender Physiklehrkräfte in verschiedenen Ausbildungsformen. Empirische Hinweise für eine Verbesserung des Lehramtsstudiums. Z. Erzieh. 2012, 15, 111-143. [CrossRef]

74. Dollny, S.; Tepner, O. CK und PCK von Chemielehrkräften-Unterschiede und Zusammenhänge. In Konzepte fachdidaktischer Strukturierung für den Unterricht, Proceedings of the Annual Meeting of the Society for the Principles of Teaching Chemistry and Physics (GDCP), Oldenburg, Germany, 19-22 November 2011; Bernholt, S., Ed.; LIT-Verlag: Münster, Germany, 2012; pp. $212-214$.

75. Riese, J.; Reinhold, P. Empirische Erkenntnisse zur Struktur professioneller Handlungskompetenz von angehenden Physiklehrkräften. Z. Didakt. Nat. 2010, 16, 167-187.

76. Rohaan, E.J. Testing Teacher Knowledge for Technology Teaching in Primary Schools. Ph.D. Thesis, Eindhoven University of Technology, Eindhoven, The Netherlands, 2009. [CrossRef]

77. Tröbst, S.; Kleickmann, T.; Heinze, A.; Anschütz, A.; Rink, R.; Kunter, M. Teacher knowledge experiment: Testing mechanisms underlying the formation of preservice elementary school teachers' pedagogical content knowledge concerning fractions and fractional arithmetic. J. Educ. Psychol. 2018, 110, 1049-1065. [CrossRef]

78. Bromme, R. Kompetenzen, Funktionen und unterrichtliches Handeln des Lehrers. In Enzyklopädie der Psychologie. Serie 1: Pädagogische Psychologie. Psychologie des Unterrichts und der Schule; Weinert, F.E., Ed.; Hogrefe: Göttingen, Germany, 1997; Volume 3, pp. 177-212.

79. Lange, K. Professionelle Kompetenzen von Lehrkräften im Sachunterricht. In Handbuch Didaktik des Sachunterrichts, , 2nd ed.; Kahlert, J., Fölling-Albers, M., Götz, M., Hartinger, A., Miller, S., Wittkowske, S., Eds.; Klinkhardt: Bad Heilbrunn, Germany, 2015; pp. 82-87.

80. Kallery, M. Early-Years Teachers' Professional Upgrading in Science: A Long-Term Programme. Res. Sci. Educ. 2018, 48, 437-464. [CrossRef]

81. Sabel, J.L.; Forbes, C.T.; Flynn, L. Elementary teachers' use of content knowledge to evaluate students' thinking in the life sciences Int. J. Sci. Educ. 2016, 38, 1077-1099. [CrossRef]

82. Putnam, R.T.; Heaton, R.M.; Prawat, R.S.; Remillard, J. Teaching Mathematics for Understanding: Discussing Case Studies of Four Fifth-Grade Teachers. Elem. Sch. J. 1992, 93, 213-228. [CrossRef]

83. Tobin, K.; Tippins, D.J.; Gallard, A.J. Research on Instructional Strategies for Teaching Science. In Handbook of Research on Science Teaching and Learning; Gabel, D.L., Ed.; Macmillan Publishing Company: New York, NY, USA, 1994; pp. 45-93.

84. Baumert, J.; Blum, W.; Neubrand, M. Drawing the lessons from PISA 2000. Z. Erzieh. 2004, 7, 143-157. [CrossRef] 
85. Luera, G.R.; Moyer, R.H.; Everett, S.A. What type and level of science content knowledge of elementary education students affect their ability to construct an inquiry-based science lesson? J. Elem. Sci. Educ. 2005, 17, 12-25. [CrossRef]

86. Rohaan, E.J.; Taconis, R.; Jochems, W.M.G. Analysing teacher knowledge for technology education in primary schools. Int. J. Technol. Des. Educ. 2012, 22, 271-280. [CrossRef]

87. Schoon, K.J.; Boone, W.J. Self-efficacy and alternative conceptions of science of preservice elementary teachers. Sci. Educ. 1998, 82, 553-568. [CrossRef]

88. Velthuis, C.; Fisser, P.; Pieters, J. Teacher Training and Pre-service Primary Teachers' Self-Efficacy for Science Teaching. J. Sci. Teach. Educ. 2014, 25, 445-464. [CrossRef]

89. Heller, J.I.; Daehler, K.R.; Wong, N.; Shinohara, M.; Miratrix, L. Differential Effects of Three Professional Development Models on Teacher Knowledge and Student Achievement in Elementary Science. J. Res. Sci. Teach. 2012, 49, 333-362. [CrossRef]

90. Hill, H.C.; Rowan, B.; Ball, D.L. Effects of Teachers' Mathematical Knowledge for Teaching on Student Achievement. Am. Educ. Res. J. 2005, 42, 371-406. [CrossRef]

91. Ohle, A.; Fischer, H.E.; Kauertz, A. Der Einfluss des physikalischen Fachwissens von Primarstufenlehrkräften auf Unterrichtsgestaltung und Schülerleistung. Z. Didakt. Nat. 2011, 17, 357-389.

92. Secretariat of the Standing Conference of the Ministers of Education and Cultural Affairs of the Länder in the Federal Republic of Germany. Ländergemeinsame Inhaltliche Anforderungen für Die Fachwissenschaften und Fachdidaktiken in der Lehrerbildung (Beschluss vom 16.10.2008 i. d. F. vom 16.05.2019). Available online: https:/ / www.kmk.org/fileadmin/veroeffentlichungen_ beschluesse/2008/2008_10_16-Fachprofile-Lehrerbildung.pdf (accessed on 8 September 2021).

93. Blömeke, S.; Kaiser, G.; Lehmann, R.; König, J.; Döhrmann, M.; Buchholtz, C.; Hacke, S. TEDS-M: Messung von Lehrerkompetenzen im internationalen Vergleich. In Lehrprofessionalität. Bedingungen, Genese, Wirkungen und Ihre Messung; Zlatkin-Troitschanskaia, O., Beck, K., Sembrill, D., Nickolaus, R., Mulder, R., Eds.; Beltz: Weinheim, Germany, 2009; pp. 181-210.

94. Anders, Y.; Hardy, I.; Sodian, B.; Steffensky, M. Zieldimensionen naturwissenschaftlicher Bildung im Grundschulalter und ihre Messung. In Wissenschaftliche Untersuchungen zur Arbeit der Stiftung "Haus der Kleinen Forschung"; der Kleinen Forscher, S.H., Ed.; SCHUBI Lernmedien: Schaffhausen, Germany, 2013; pp. 83-146.

95. Döhrmann, M.; Kaiser, G.; Blömeke, S. The Conceptualisation of Mathematics Competencies in the International Teacher Education Study TEDS-M. In International Perspectives on Teacher Knowledge, Beliefs and Opportunities to Learn; Blömeke, S., Hsieh, F.-J., Kaiser, G., Schmidt, W.H., Eds.; Springer: Dordrecht, The Netherlands, 2014; pp. 431-456. [CrossRef]

96. Ohle, A. Primary School Teachers' Content Knowledge in Physics and Its Impact on Teaching and Students' Achievement; Logos: Berlin, Germany, 2010.

97. Tatto, M.T.; Schwille, J.; Senk, S.L.; Ingvarson, L.; Peck, R.; Rowley, G. Teacher Education and Development Study in Mathematics (TEDS-M). Policy, Practice, and Readiness to Teach. Primary and Secondary Mathematics. Conceptual Framework; Teacher Education and Development International Study Center, College of Education, Michigan State University: East Lansing, MI, USA, 2008.

98. Ohle, A.; Boone, W.J.; Fischer, H.E. Investigating the impact of teachers' physics CK on students outcomes. Int. J. Sci. Math. Educ. 2015, 13, 1211-1233. [CrossRef]

99. Arzi, H.J.; White, R.T. Change in teachers' knowledge of subject matter: A 17-year longitudinal study. Sci. Educ. 2008, 92, 221-251. [CrossRef]

100. Brunner, M.; Kunter, M.; Krauss, S.; Baumert, J.; Blum, W.; Dubberke, T.; Jordan, A.; Klusmann, U.; Tsai, Y.M.; Neubrand, M. Welche Zusammenhänge bestehen zwischen dem fachspezifischen Professionswissen von Mathematiklehrern und ihrer Ausbildung sowie beruflichen Fortbildung? Z. Erzieh. 2006, 9, 521-544. [CrossRef]

101. Summers, M.; Kruger, C. A longitudinal study of constructivist approach to improving primary science teachers' subject matter knowledge in science. Teach. Teach. Educ. 1994, 10, 499-519. [CrossRef]

102. Kratz, J.; Schaal, S.; Heran-Dörr, E. Fachwissen von Lehramtsstudierenden zum Thema "Leben in extremen klimatischen Bedingungen"-Erhebung des Fachwissens im Rahmen einer Interventionsstudie. J. GDSU 2013, 3, 23-36.

103. Desimone, L.M. Improving Impact Studies of Teachers' Professional Development: Toward Better Conceptualizations and Measures. Educ. Res. 2009, 38, 181-199. [CrossRef]

104. Möller, K. Konstruktivistische Sichtweisen für das Lernen in der Grundschule? In Forschungen zu Lehr-Und Lernkonzepten für Die Grundschule (Jahrbuch Grundschulforschung, 4); Roßbach, H.-G., Nölle, K., Czerwenka, K., Eds.; Leske + Budrich: Opladen, Germany, 2001; pp. 16-31.

105. Riemeier, T. Moderater Konstruktivismus. In Theorien in der Biologiedidaktischen Forschung; Krüger, D., Vogt, H., Eds.; Springer: Berlin/Heidelberg, Germany, 2007; pp. 69-79. [CrossRef]

106. Möller, K.; Hardy, I.; Jonen, A.; Kleickmann, T.; Blumberg, E. Naturwissenschaften in der Primarstufe. Zur Förderung konzeptuellen Verständnisses durch Unterricht und zur Wirksamkeit von Lehrerfortbildungen. In Untersuchungen zur Bildungsqualität von Schule. Abschlussbericht des DFG-Schwerpunktprogramms BiQua; Prenzel, M., Allolio-Näcke, L., Eds.; Waxmann: Münster, Germany, 2006; pp. 161-193.

107. Kunter, M.; Klusmann, U.; Baumert, J.; Richter, D.; Voss, T.; Hachfeld, A. Professional competences of teachers: Effects on instructional quality and student development. J. Educ. Psychol. 2013, 105, 805-820. [CrossRef]

108. Shavelson, R.J.; Hubner, J.J.; Stanton, G.C. Self-Concept: Validation of Construct Interpretations. Rev. Educ. Res. 1976, 46, 407-441. [CrossRef] 
109. Ghazvini, S.D. Relationships between Academic Self-concept and Academic Performance in High School Students. Procedia-Soc. Behav. Sci. 2011, 15, 1034-1039. [CrossRef]

110. Möller, J.; Trautwein, U. Selbstkonzept. In Pädagogische Psychologie, 2nd ed.; Wild, E., Möller, J., Eds.; Springer: Heidelberg, Germany, 2015; pp. 177-199. [CrossRef]

111. Marsh, H.W.; Shavelson, R.J. Self-Concept: Its Multifaceted, Hierarchical Structure. Educ. Psychol. 1985, 20, 107-125. [CrossRef]

112. Marsh, H.W.; Byrne, B.M.; Shavelson, R.J. A multifaceted academic self-concept: Its hierarchical structure and its relation to academic achievement. J. Educ. Psychol. 1988, 80, 366-380. [CrossRef]

113. Marsh, H.W. The structure of academic self-concept: The Marsh/Shavelson model. J. Educ. Psychol. 1990, 82, 623-636. [CrossRef]

114. Möller, J.; Köller, O. Die Genese akademischer Selbstkonzepte. Psychol. Rundsch. 2004, 55, 19-27. [CrossRef]

115. Adenstedt, V. Pilotierung eines Fragebogens zur Erhebung des Technischen Selbstkonzepts von durchschnittlich Neunjährigen. J. Tech. Educ. 2018, 6, 9-29.

116. Paulick, I.; Großschedl, J.; Harms, U.; Möller, J. Preservice Teachers' Professional Knowledge and Its Relation to Academic Self-Concept. J. Teach. Educ. 2016, 67, 173-182. [CrossRef]

117. Sorge, S.; Keller, M.M.; Neumann, K.; Möller, J. Investigating the relationship between pre-service physics teachers' professional knowledge, self-concept, and interest. J. Res. Sci. Teach. 2019, 56, 937-955. [CrossRef]

118. Kleickmann, T.; Tröbst, S.; Jonen, A.; Vehmeyer, J.; Möller, K. The Effects of Expert Scaffolding in Elementary Science Professional Development on Teachers' Beliefs and Motivations, Instructional Practices, and Student Achievement. J. Educ. Psychol. 2015, 108, 21-42. [CrossRef]

119. Peschel, M. SelfPro: Entwicklung von Professionsverständnissen und Selbstkonzepten angehender Lehrkräfte beim Offenen Experimentieren. In Profession und Disziplin. Jahrbuch Grundschulforschung; Miller, S., Holler-Nowitzki, B., Kottmann, B., Lesemann, S., Letmathe-Henkel, B., Meyer, N., Schroeder, R., Velten, K., Eds.; Springer: Wiesbaden, Germany, 2018; Volume 22, pp. 191-196. [CrossRef]

120. Janssen, M.K. Mit biologischen Inhalten Brücken zur Chemie bauen. Entwicklung und Erprobung Eines Seminars für Sachunterrichtsstudierende. Ph.D. Thesis, University of Siegen, Siegen, Germany, 2015.

121. Gabriel-Busse, K.; Kastens, C.P.; Kucharz, D. Fachspezifisch oder nicht?-Eine Studie zur Analyse der Binnenstruktur des Selbstkonzepts Sachunterricht. Z. Grund. 2018, 11, 333-348. [CrossRef]

122. Wigfield, A.; Eccles, J.S. The development of achievement task values: A theoretical analysis. Dev. Rev. 1992, 12, 265-310. [CrossRef]

123. Helmke, A.; van Aken, M.A.G. The causal ordering of academic achievement and self-concept of ability during elementary school: A longitudinal study. J. Educ. Psychol. 1995, 87, 624-637. [CrossRef]

124. Valentine, J.C.; DuBois, D.L.; Cooper, H. The Relation Between Self-Beliefs and Academic Achievement: A Meta-Analytic Review. Educ. Psychol. 2004, 39, 111-133. [CrossRef]

125. Guskey, T.R. Teacher efficacy, self-concept, and attitudes toward the implementation of instructional innovation. Teach. Teach. Educ. 1988, 4, 63-69. [CrossRef]

126. Hughes, T.M. The Prediction of Teacher Burnout through Personality Type, Critical Thinking, and Self-Concept. In Proceedings of the Annual Meeting of the Mid-South Educational Research Association, Mobile, AL, USA, 11-13 November 1987.

127. Aspy, D.N.; Buhler, J.H. The Effect of Teacher's Inferred Self Concept upon Student Achievement. J. Educ. Res. 1975, 68, 386-389. [CrossRef]

128. Marsh, H.W.; Craven, R.G. Reciprocal Effects of Self-Concept and Performance from a Multidimensional Perspective: Beyond Seductive Pleasure and Unidimensional Perspectives. Perspect. Psychol. Sci. 2006, 1, 133-162. [CrossRef]

129. Hill, H.C. The Nature and Predictors of Elementary Teachers' Mathematical Knowledge for Teaching. J. Res. Math. Educ. 2010, 41, 513-545. [CrossRef]

130. Buse, M.; Damerau, K.; Preisfeld, A. A scientific out-of-school programme on neurobiology employing CLIL. Its impact on the cognitive acquisition and experimentation-related ability self-concepts. Int. J. Environ. Sci. Educ. 2018, 13, 647-660.

131. Damerau, K. Molekulare und Zell-Biologie im Schülerlabor. Ph.D. Thesis, University of Wuppertal, Wuppertal, Germany, 2012.

132. Paulick, I.; Großschedl, J.; Harms, U.; Möller, J. How teachers perceive their expertise: The role of dimensional and social comparisons. Contemp. Educ. Psychol. 2017, 51, 114-122. [CrossRef]

133. Marsh, H.W.; Salah Abduljabbar, A.; Parker, P.D.; Abdelfattah, F.; Nagengast, B.; Möller, J.; Abu-Hilal, M.M. The Internal/External Frame of Reference Model of Self-Concept and Achievement Relations: Age-Cohort and Cross-Cultural Differences. Am. Educ. Res. J. 2015, 52, 168-202. [CrossRef]

134. Wolff, F.; Helm, F.; Zimmermann, F.; Nagy, G.; Möller, J. On the Effects of Social, Temporal, and Dimensional Comparisons on Academic Self-Concept. J. Educ. Psychol. 2018, 110, 1005-1025. [CrossRef]

135. Bong, M.; Skaalvik, E.M. Academic Self-Concept and Self-Efficacy: How Different Are They Really? Educ. Psychol. Rev. 2003, 15, 1-40. [CrossRef]

136. Lüdtke, O.; Köller, O.; Marsh, H.W.; Trautwein, U. Teacher frame of reference and the big-fish-little-pond effect. Contemp. Educ. Psychol. 2005, 30, 263-285. [CrossRef]

137. Beudels, M.; Preisfeld, A.; Damerau, K. Impact of an Experiment-Based Intervention on Pre-Service Primary School Teachers' Experiment-Related and Science Teaching-Related Self-Concepts. Interdiscip. J. Environ. Sci. Educ. 2022, 18, e2258. [CrossRef] 
138. Franken, N.; Damerau, K.; Preisfeld, A. “Experimentieren kann ich gut!“—Experimentbezogene Fähigkeitsselbstkonzepte von Lehramtsstudierenden der Fächer Biologie, Chemie und Sachunterricht. Z. Didakt. Biol.-Biol. Lehre. Lern. 2020, $24,48-66$. [CrossRef]

139. Labudde, P. Fächerübergreifender naturwissenschaftlicher Unterricht-Mythen, Definitionen, Fakten. Z. Didakt. Nat. 2014, 20, 11-19. [CrossRef]

140. Schwichow, M.; Zaki, K.; Hellmann, K.; Kreutz, J. Quo vadis? Kohärenz in der Lehrerbildung. In Kohärenz in der Lehrerbildung; Hellmann, K., Kreutz, J., Schwichow, M., Zaki, K., Eds.; Springer: Wiesbaden, Germany, 2019; pp. 331-350. [CrossRef]

141. Labudde, P. Fächerübergreifender Unterricht in und mit Physik: Eine zu wenig genutzte Chance. PhyDid-A 2003, 1, 48-66.

142. Aström, M. Defining Integrated Science Education and Putting It to Test. Ph.D. Thesis, Linköping University, Norrköping, Sweden, 2008.

143. Menon, D.; Sadler, T.D. Preservice Elementary Teachers' Science Self-Efficacy Beliefs and Science Content Knowledge. J. Sci. Teach. Educ. 2016, 27, 649-673. [CrossRef]

144. Niermann, A. Professionswissen von Lehrerinnen und Lehrern des Mathematik—und Sachunterrichts; Klinkhardt: Bad Heilbrunn, Germany, 2017.

145. Gerdes, A. Zur Wirksamkeit von Integriertem Naturwissenschaftlichem Unterricht. Ph.D. Thesis, University of Kassel, Kassel, Germany, 2001.

146. Federal Statistical Office. Lehrkräfte nach Schularten und Beschäftigung. Schuljahr 2019/20. Stand: 20. Oktober 2020. Available online: https:/ / www.destatis.de/DE/Themen/Gesellschaft-Umwelt/Bildung-Forschung-Kultur/Schulen/Tabellen/ allgemeinbildende-beruflicheschulen-lehrkraefte.html (accessed on 8 September 2021).

147. Rehfeldt, D.; Straube, P.; Köster, H. Längsschnittstudie im Grundschulpädagogik-Sachunterrichtsstudium: Selbstkonzepte \& Überzeugungen (1-Jahres-Daten). In Naturwissenschaftliche Kompetenzen in der Gesellschaft von Morgen, Proceedings of the Annual Meeting of the Society for the Principles of Teaching Chemistry and Physics (GDCP), Wien, Australia, 9-12 September 2019; Habig, S., Ed.; University of Duisburg-Essen: Duisburg/Essen, Germany, 2020; pp. 924-927.

148. Fischer, H.; Peters, B. Blockveranstaltungen—Lehrformat für Eine Heterogene Studierendenschaft; Discussion Paper 1; Zentrum für Hochschulbildung, TU Dortmund University: Dortmund, Germany, 2012. Available online: https://d-nb.info/1112267018/34 (accessed on 8 September 2021).

149. French, S. The Benefits and Challenges of Modular Higher Education Curricula; Issues and Ideas Paper; Melbourne Centre for the Study of Higher Education, The University of Melbourne: Parkville, Australia, 2015. Available online: https://melbourne-cshe.unimelb. edu.au/_data/assets/pdf_file/0006/2774391/Benefits_Challenges_Modular_Higher_Ed_Curricula_SFrench_v3-green-2.pdf (accessed on 8 September 2021).

150. Samarawickrema, G.; Cleary, K. Block Mode Study: Opportunities and Challenges for a New Generation of Learners in an Australian University. Stud. Success 2021, 12, 13-23. [CrossRef]

151. Burton, S.; Nesbit, P.L. Block or traditional? An analysis of student choice of teaching format. J. Manag. Organ. 2008, 14, 4-19. [CrossRef]

152. Holley, D.; Park, S. Lessons learned around the block: An analysis of research on the impact of block scheduling on science teaching and learning. In Education Research Highlights in Mathematics, Science, and Technology; Shelley, M., Pehlivan, M., Eds.; ISRES Publishing: Ames, IA, USA, 2017; pp. 132-138.

153. Dixon, L.; O'Gorman, V. 'Block teaching'-exploring lecturers' perceptions of intensive modes of delivery in the context of undergraduate education. J. Furth. High. Educ. 2019, 44, 583-595. [CrossRef]

154. Hilkenmeier, J.; Sommer, S. Praxisnahe Fallarbeit-Block versus wöchentliches Seminar. Ein Vergleich zweier Veranstaltungsformate in der Lehrerinnen-und Lehrerbildung. Beiträge Lehr.-Lehr. 2014, 32, 88-100.

155. Metzger, C.; Haag, J. Ich könnte nie wieder zu einem, normalen “Stundenplan zurück!”-Zur Reorganisation der Lehre in einem Bachelor-Studiengang IT Security. In HDI 2012-Informatik für Eine Nachhaltige Zukunft, Proceedings of the 5th Symposium Hochschuldidaktik der Informatik, Hamburg, Germany, 6-7 November 2012; Forbrig, P., Rick, D., Schmolitzky, A., Eds.; Universitätsverlag Potsdam: Potsdam, Germany, 2013; pp. 67-78.

156. Kucsera, J.V.; Zimmaro, D.M. Comparing the Effectiveness of Intensive and Traditional Courses. Coll. Teach. 2010, 58, 62-68. [CrossRef]

157. Caskey, S.R. Learning Outcomes in Intensive Courses. J. Contin. High. Educ. 1994, 42, 23-27. [CrossRef]

158. Daniel, E.L. A Review of Time-Shortened Courses across Disciplines. Coll. Stud. J. 2000, 34, $298-308$.

159. Schaal, S.; Randler, S. Konzeption und Evaluation eines computergestützten kooperativen Blockseminars zur Systematik der Blütenpflanzen. Z. Hochsch. 2004, 2, 1-18. [CrossRef]

160. van Scyoc, L.J.; Gleason, J. Traditional or Intensive Course Lengths? A Comparison of Outcomes in Economics Learning. J. Econ. Educ. 1993, 24, 15-22. [CrossRef]

161. Henebry, K. The Impact of Class Schedule on Student Performance in a Financial Management Course. J. Educ. Bus. 1997, 73, 114-120. [CrossRef]

162. Petrowsky, M.C. The Two Week Summer Macroeconomics Course: Success or Failure; Glendale Community College: Glendale, AZ, USA, 1996. Available online: https:/ / files.eric.ed.gov/fulltext/ED396779.pdf (accessed on 8 September 2021).

163. McCreary, J.; Hausman, C. Differences in Student Outcomes between Block, Semester, and Trimester Schedules; University of Utah: Salt Lake City, UT, USA, 2001. Available online: https:/ files.eric.ed.gov/fulltext/ED457590.pdf (accessed on 8 September 2021). 
164. Wilson, E.; Looney, S.; Stair, K. The Impact of Block Scheduling on Agricultural Education: A Nine Year Comparative Study. J. Career Tech. Educ. 2005, 22, 43-54. [CrossRef]

165. Spence, M.J. Block Versus Traditional Scheduling in High School: Teacher and Student Attitudes. Ph.D. Thesis, Lindenwood University, St. Charles, MO, USA, 1 July 2020.

166. Yang, J.; Zhan, L.; Wang, Y.; Du, X.; Zhou, W.; Ning, X.; Sun, Q.; Moscovitch, M. Effects of learning experience on forgetting rates of item and associative memories. Learn. Mem. 2016, 23, 365-378. [CrossRef]

167. Bateson, D.J. Science Achievement in Semester and All-Year Courses. J. Res. Sci. Teach. 1990, 27, 233-240. [CrossRef]

168. Wodzinski, R. Physikalische Fachkonzepte anbahnen-Anschlussfähigkeit verbessern. In Physikdidaktik Grundlagen, 4th ed.; Kircher, E., Girdwidz, R., Fischer, H.E., Eds.; Springer Spektrum: Berlin, Germany, 2020; pp. 573-602. [CrossRef]

169. Cramer, C. Kohärenz und Relationierung in der Lehrerinnen-und Lehrerbildung. In Handbuch Lehrerinnen—und Lehrerbildung; Cramer, C., König, J., Rothland, M., Blömeke, S., Eds.; Klinkhardt: Bad Heilbrunn, Germany, 2020; pp. 269-279. [CrossRef]

170. Randler, C.; Kranich, K.; Eisele, M. Block scheduled versus traditional biology teaching-An educational experiment using the water lily. Instr. Sci. 2008, 36, 17-25. [CrossRef]

171. Beudels, M.; Schilling, Y.; Preisfeld, A. Mit Experimenten zu Wasserläufer \& Co Kohärenz Erleben-Potenziale Eines Interdisziplinären, Experimentellen Kurses zur Professionalisierung Angehender Sachunterrichtslehrkräfte. DiMaWe. Under Review.

172. Kaiser, A. Praxisbuch Handelnder Sachunterricht (Band 4); Schneider Hohengehren: Baltmannsweiler, Germany, 2014.

173. Wagenschein, M. Teaching to Understand: On the Concept of the Exemplary in Teaching. In Teaching as A Reflective Practice. The German Didaktik Tradition; Westbury, I., Hopmann, S.T., Riquarts, K., Eds.; Lawrence Erlbaum: Mahwah, NJ, USA, 2000; pp. 161-175.

174. Ministry for School and Further Education North Rhine-Westphalia (MSW NRW). Richtlinien und Lehrpläne für die Grundschule in Nordrhein-Westfalen; Ritterbach: Frechen, Germany, 2008.

175. Macke, G.; Hanke, U.; Viehmann-Schweizer, P.; Raether, W. Kompetenzorientierte Hochschuldidaktik, 3rd ed.; Beltz: Weinheim, Germany, 2016.

176. Prenzel, M.; Geiser, H.; Langeheine, R.; Lobemeier, K. Das naturwissenschaftliche Verständnis am Ende der Grundschule. In Erste Ergebnisse aus IGLU; Bos, W., Lankes, E.-M., Prenzel, M., Schwippert, K., Valtin, R., Walther, G., Eds.; Waxmann: Münster, Germany, 2003; pp. 143-187.

177. Stampfl, M.; Saurer, W. Hinterlässt der Physikunterricht Spuren?-Das Interesse am Physikunterricht im Rückblick von Studierenden. PhyDid A-Phys. Didakt. Sch. Hochsch. 2020, 1, 1-11.

178. Posner, G.J.; Strike, K.A.; Hewson, P.W.; Gertzog, W.A. Accommodation of a Scientific Conception: Toward a Theory of Conceptual Change. Sci. Educ. 1982, 66, 211-227. [CrossRef]

179. Giest, H. Die Naturwissenschaftliche Perspektive Konkret; Klinkhardt: Bad Heilbrunn, Germany, 2017.

180. Mammes, I.; Zolg, M. Technische Aspekte. In Handbuch Didaktik des Sachunterrichts, 2nd ed.; Kahlert, J., Fölling-Albers, M., Götz, M., Hartinger, A., Miller, S., Wittkowske, S., Eds.; Klinkhardt: Bad Heilbrunn, Germany, 2015; pp. $143-149$.

181. SoSci Survey (Computer Software). Available online: https:/ / www.soscisurvey.de/ (accessed on 8 September 2021).

182. Rost, J. Lehrbuch Testtheorie-Testkonstruktion, 2nd ed.; Huber: Bern, Switzerland, 2004.

183. Lipton, A.; Huxham, G.J. Comparison of multiple-choice and essay testing in preclinical physiology. Br. J. Med. Educ. 1970, 4 , 228-238. [CrossRef] [PubMed]

184. Bridgeman, B.; Lewis, C. The Relationship of Essay and Multiple-choice Scores with Grades in College Courses. J. Educ. Meas. 1994, 31, 37-50. [CrossRef]

185. Strack, F. "Order Effects" in Survey Research: Activation and Information Functions of Preceding Questions. In Context Effects in Social and Psychological Research; Schwarz, N., Sudman, S., Eds.; Springer: New York, NY, USA, 1992; pp. 23-34. [CrossRef]

186. Bühner, M. Einführung in Die Test-Und Fragebogenkonstruktion, 4th ed.; Pearson: München, Germany, 2021.

187. Kauertz, A.; Kleickmann, T.; Ewerhardy, A.; Fricke, K.; Lange, K.; Ohle, A.; Pollmeier, K.; Tröbst, S.; Walper, L.; Fischer, H.; et al. Dokumentation der Erhebungsinstrumente im Projekt PLUS; Forschergruppe und Graduiertenkolleg nwu-essen: Duisburg/Essen, Germany, 2011.

188. Kaiser, H.F.; Rice, J. Little Jiffy, Mark IV. Educ. Psychol. Meas. 1974, 34, 111-117. [CrossRef]

189. Janssen, J.; Laatz, W. Statistische Datenanalyse Mit SPSS, 9th ed.; Springer Gabler: Berlin, Germany, 2017. [CrossRef]

190. Bartlett, M.S. The Effect of Standardization on a Chi Square Approximation in Factor Analysis. Biometrika 1951, 38, 337-344. [CrossRef]

191. Backhaus, K.; Erichson, B.; Wulff, P.; Weiber, R. Multivariate Analysemethoden, 15th ed.; Springer Gabler: Berlin/Heidelberg, Germany, 2018. [CrossRef]

192. Noormann, P. Mehrstufige Eigenmarken-Eine Empirische Analyse von Zielen, Erfolgsdeterminanten und Grenzen; Springer Gabler: Wiesbaden, Germany, 2017. [CrossRef]

193. Fromm, S. Faktoren-Und Reliabilitätsanalyse [Factor and Reliability Analysis]. In Datenanalyse mit SPSS für Fortgeschrittene 2: Multivariate Verfahren für Querschnittsdaten; Fromm, S., Ed.; Springer: Wiesbaden, Germany, 2012; pp. 53-82. [CrossRef]

194. MacCallum, R.C.; Widaman, K.F.; Zhang, S.; Hong, S. Sample size in factor analysis. Psychol. Methods 1999, 4, 84-99. [CrossRef]

195. Döring, N.; Bortz, J. Forschungsmethoden und Evaluation in Den Sozial-Und Humanwissenschaften, 5th ed.; Springer: Berlin/Heidelberg, Germany, 2016. [CrossRef] 
196. George, D.; Mallery, P. SPSS for Windows Step by Step: A Simple Guide and Reference. 11.0 Update, 4th ed.; Allyn \& Bacon: Boston, MA, USA, 2003.

197. Kline, R.B. Principles and Practice of Structural Equation Modeling, 3rd ed.; The Guilford Press: New York, NY, USA, 2011.

198. Rasch, B.; Friese, M.; Hofmann, W.; Naumann, E. Quantitative Methoden 2, 4th ed.; Springer: Berlin/Heidelberg, Germany, 2014. [CrossRef]

199. Girden, E.R. ANOVA: Repeated Measures; Sage University Papers; Quantitative Applications in the Social Sciences: No. 07-084; Sage Publications: Newbury Park, CA, USA, 1992.

200. Rasch, B.; Friese, M.; Hofmann, W.; Naumann, E. Quantitative Methoden 1, 4th ed.; Springer: Berlin/Heidelberg, Germany, 2014. [CrossRef]

201. Cohen, J. Statistical Power Analysis for the Behavioral Sciences, 2nd ed.; Lawrence Erlbaum: New York, NY, USA, 1988.

202. Albert, R.; Koster, C.J. Empirie in Linguistik und Sprachlehrforschung. In Ein Methodologisches Arbeitsbuch; Narr: Tübingen, Germany, 2002.

203. Bühl, A. Einführung in Die Moderne Datenanalyse ab SPSS 25, 16th ed.; Pearson: Hallbergmoos, Germany, 2019.

204. Jansen, M.; Schroeders, U.; Lüdtke, O.; Pant, H.A. Der Einfluss interdisziplinärer Beschulung auf die Struktur des akademischen Selbstkonzepts in den naturwissenschaftlichen Fächern. Z. Pädagog. Psychol. 2014, 28, 43-49. [CrossRef]

205. Jansen, M. Academic Self-Concept in the Sciences: Domain-Specific Differentiation, Gender Differences, and Dimensional Comparison Effects. In Self: Driving Positive Psychology and Well-Being; Guay, F., Marsh, H.W., McInerney, D.M., Craven, R.G., Eds.; IAP Information Age Publishing: Charlotte, NC, USA, 2017; pp. 71-112.

206. Möller, J.; Marsh, H.W. Dimensional comparison theory. Psychol. Rev. 2013, 120, 544-560. [CrossRef]

207. Marsh, H.W.; Trautwein, U.; Lüdtke, O.; Köller, O.; Baumert, J. Academic Self-Concept, Interest, Grades, and Standardized Test Scores: Reciprocal Effects Models of Causal Ordering. Child. Dev. 2005, 76, 397-416. [CrossRef]

208. Canady, R.L. Parallel Block Scheduling: A Better Way to Organize School. Principal 1990, 69, 34-36.

209. Scott, P.A. Attributes of high-quality intensive courses. New Dir. Adult Cont. Educ. 2003, 29-38. [CrossRef]

210. Davies, M. Intensive teaching formats: A review. Issues Educ. Res. 2006, 15, 1-20.

211. Groß, L.; Aufenanger, S. Wie wirken didaktische Elemente der Hochschullehre auf die zeitliche Gestaltung des Studiums? Z. Hochsch. 2011, 6, 123-132. [CrossRef]

212. Richter, D. Lernen im Beruf. In Professionelle Kompetenz von Lehrkräften. Ergebnisse des Forschungsprogramms COACTIV; Kunter, M., Baumert, J., Blum, W., Klusmann, U., Krauss, S., Neubrand, M., Eds.; Waxmann: Münster, Germany, 2011; pp. $317-327$.

213. Hill, H.C.; Schilling, S.G.; Ball, D.L. Developing Measures of Teachers' Mathematics Knowledge for Teaching. Elem. Sch. J. 2004, 105, 11-30. [CrossRef]

214. Fendler, L. Ethical implications of validity-vs.-reliability trade-offs in educational research. Ethics Educ. 2016, 11, 214-229. [CrossRef]

215. Phakiti, A. Experimental Research Methods in Language Learning; Bloomsbury Publishing: New York, NY, USA, 2014.

216. Lange, K.; Ohle, A.; Kleickmann, T.; Kauertz, A.; Möller, K.; Fischer, H.E. Zur Bedeutung von Fachwissen und fachdidaktischem Wissen für Lernfortschritte von Grundschülerinnen und Grundschülern im naturwissenschaftlichen Sachunterricht. Z. Grund. 2015, 8, 23-38.

217. Hasler, M. Bionik: Klettverschluss, Flugzeug und Co; Lernbiene: Bavaria, Germany, 2016.

218. Kalusche, D.; Kremer, B.P. Biologie in der Grundschule. In Spannende Projekte für Einen Lebendigen Unterricht und für Arbeitsgemeinschaften; Schneider Hohengehren: Baltmannsweiler, Germany, 2010.

219. Barthlott, W.; Neinhuis, C. Lotus-Effekt und Autolack: Die Selbstreinigungsfähigkeit mikrostrukturierter Oberflächen. Biol. Zeit 1998, 28, 314-321. [CrossRef]

220. Ganz, G.; Pietrzyk, U.; Schneider, K.; Willmer-Klumpp, C. Naturwissenschaften Kompakt Gymnasium Sek. I; Ernst Klett: Stuttgart, Germany, 2007.

221. Job, G.; Rüffler, R. Physikalische Chemie. Eine Einführung Nach Neuem Konzept mit Zahlreichen Experimenten; Vieweg+Teubner/ Springer: Wiesbaden, Germany, 2011.

222. Nachtigall, W. Bionik als Wissenschaft. Erkennen-Abstrahieren-Umsetzen; Springer: Berlin/Heidelberg, Germany, 2010. [CrossRef]

223. Nachtigall, W.; Pohl, G. Bau-Bionik. Natur-Analogien-Technik, 2nd ed.; Springer: Berlin/Heidelberg, Germany, 2013. [CrossRef]

224. Nachtigall, W.; Wisser, A. Bionik in Beispielen. 250 Illustrierte Ansätze; Springer Spektrum: Berlin/Heidelberg, Germany, 2013. [CrossRef]

225. Borchers, J. Spannende Sachtexte zum Körper. Kopiervorlagen für den Deutsch-Und Sachunterricht ab 2. Klasse, 5th ed.; Persen: Hamburg, Germany, 2016.

226. Drechsler-Köhler, B. Bausteine Sachunterricht 4 für Nordrhein-Westfalen; Diesterweg: Braunschweig, Germany, 2004.

227. Ganser, B.; Simon, I. Forscher Unterwegs; Brigg Pädagogik: Augsburg, Germany, 2009.

228. Haider, M.; Hartinger, A. Experimentieren im Sachunterricht; Cornelsen Scriptor: Berlin, Germany, 2010.

229. Weber, S.; Hoenecke, C. Lernen an Stationen-Themenheft "Experimentieren mit Luft: 3./4. Schuljahr"; Cornelsen Scriptor: Berlin, Germany, 2005.

230. Dietrich, V.; Mederow, G. Naturwissenschaften Biologie-Chemie—Physik: Luft; Volk und Wissen Verlag: Berlin, Germany, 2002.

231. Graf, E. Atmung: Lernen an Stationen im Biologieunterricht (7. und 8. Klasse), 2nd ed.; Auer: Augsburg, Germany, 2015.

232. Asselborn, W.; Jäckel, M.; Risch, K.T.; Sieve, B.F. Chemie heute SI-Gesamtband; Schroedel Verlag: Hannover, Germany, 2013. 
233. Bannwarth, H.; Kremer, B.P.; Schulz, A. Basiswissen Physik, Chemie und Biochemie. Vom Atom. Bis zur Atmung-Für Biologen, Mediziner und Pharmazeuten, 3rd ed.; Springer Spektrum: Berlin/Heidelberg, Germany, 2013. [CrossRef]

234. Baur, A. Humanbiologie für Lehramtsstudierende. Ein Arbeits-Und Studienbuch; Springer Spektrum: Berlin, Germany, 2015. [CrossRef]

235. Clauss, W.; Clauss, C. Humanbiologie Kompakt; Spektrum Akademischer Verlag: Heidelberg, Germany, 2009. [CrossRef]

236. Schmidt, C.; Dietrich, L. Chemie für Biologen. Von Studierenden für Studierende erklärt; Springer Spektrum: Berlin/Heidelberg, Germany, 2014. [CrossRef] 